\title{
Anti-inflammatory activity of alkaloids: A twenty-century review
}

\author{
José M. Barbosa-Filho ${ }^{1 *}$, Márcia R. Piuvezam ${ }^{1}$,Marcelo D. Moura ${ }^{1}$, Marcelo S. Silva1, Karla \\ V. Batista Lima ${ }^{1}$, Emídio V. Leitão da-Cunha ${ }^{1,2}$, Ivana M. Fechine ${ }^{3}$, Orlando S. Takemura ${ }^{4}$, \\ ${ }^{1}$ Laboratório de Tecnologia Farmacêutica "Delby Fernandes de Medeiros”, Universidade Federal da Paraíba, \\ Caixa Postal 5009, 58051-970, João Pessoa, PB, Brazil, \\ ${ }^{2}$ Departamento de Farmácia, Universidade Estadual da Paraíba, CCBN, 58100-000, \\ Campina Grande, PB, Brasil, \\ ${ }^{3}$ Departamento de Química, Universidade Estadual da Paraíba, CCEN, 58100-000, \\ Campina Grande, PB, Brasil, \\ ${ }^{4}$ Laboratorio de Farmacologia, Universidade Paranaense, Caixa-Postal 224, \\ Centro, 87502-210, Umuarama, PR, Brasil
}

\begin{abstract}
RESUMO: "Atividade anti-inflamatória de alkalóides: Uma revisão do século XX". Muitas substâncias que interferem na resposta inflamatória têm sido isoladas de plantas. Esta revisão mostra alguns alcalóides de origem vegetal que no período de 1907-2000 foram avaliados quanto a uma possível atividade anti-inflamatória. Os alcalóides foram classificados em subgrupos de acordo com suas estruturas químicas e os dados farmacológicos foram obtidos de diferentes modelos experimentais. Dos 171 alcalóides avaliados, 137 apresentaram atividade anti-inflamatória, e, entre eles, os alcalóides do tipo isoquinolínicos foram os mais estudados. O modelo de edema de pata induzido por carragenina foi o mais empregado para avaliação da atividade anti-inflamatória. Nesta revisão 174 referências foram consultadas.
\end{abstract}

Unitermos: Alcalóides, atividade anti-inflamatória, inflamação, modelos experimentais.

\begin{abstract}
Many substances which interfere with the inflammatory response have been isolated from plants. This review shows some alkaloids of vegetal origin which in the period of 1907 to 2000 were evaluated regarding a possible anti-inflammatory activity. The alkaloids were classified in sub-groups in accordance with their chemical structures and the pharmacological data were obtained from different experimental models. Of the 171 evaluated alkaloids, 137 presented anti-inflammatory activity, and among those, the isoquinoline type was the most studied. The Carrageenin-induced paw edema was the most used model for evaluating the anti-inflammatory activity. In this review, 174 references were cited.
\end{abstract}

Keywords: Alkaloids, anti-inflammatory activity, inflammation, experimental models.

\section{INTRODUCTION}

Inflammation can be defined as a generalized, nonspecific but beneficial response of tissues to injury. It comprises a complex array of adaptive responses to tissue injury which are both local and systemic. The local responses result in recruitment of phagocytic cells and removal of endogenous or foreign material. The systemic responses may alter the 'milieu interior' to allow these processes to occur more efficiently (Denko, 1992; Henson; Murphy, 1989). The cellular processes of inflammation fall into four major groups: changes in blood flow caused by changes in smooth muscle cell function causing vasodilatation, alterations in vascular permeability engendered by cytoskeletal contraction in endothelial cells, migration of phagocytic leukocytes to the site of inflammation, and phagocytosis (Denko, 1992; Evans; Whicher, 1992).
The main pathophysiological pathways for drug targeting at present are: arachidonic acid metabolism; the complement cascade; phagocytosis and other cell functions; auto-immune processes; protein kinase $\mathrm{C}$ and others enzymes involved in second messenger systems (Willianson, 1996). Early inflammation changes in damaged tissues are now known to involve the release of various biologically active materials from polymorph nuclear leukocytes, lysossomal enzymes and others. The vascular effects are primarily mediated by kinins, prostaglandins and vaso-active amines (e.g. histamine, released by mast cells), which cause increased vascular permeability leading to plasma exudation.

The inflammatory process involves a complex interplay between cells of the blood, the blood vessels themselves and the cells of the involved tissue. The process can be seen as a coordinated response of a large number of cells to an initial stimulus (Henson; Murphy, 
1989).

The immigrating cells themselves exert little effect by their presence alone, but initiate all the complex reaction of inflammation as a consequence of the materials that they secrete or release to the extra cellular environment. Such materials include molecules that exacerbate the response by attracting further inflammatory cells, inhibitors that serve to reduce the severity of the reactions, histotoxic agents such as proteases, oxygen metabolites and cations, as well as signals to the surrounding inflammatory and tissue cells to implement some or all of the complex reactions which they are capable (Henson; Murphy, 1989).

Uncontrolled inflammation is undesirable. The reversible features such as pain redness, heat and swelling are joined by a fifth and less transient feature, namely, loss of function of involved organs. Therefore control of inflammation is sought to protect the body function (Denko, 1992; Parnham, 1991).

In the field of inflammation research, several experimental models have been used to evaluate the inflammation. The usual methods of determining whether compounds have anti-inflammatory activity are to test them against animal and biochemical models of inflammation. There is no experimental model of inflammation that covers all aspects of inflammation (Lewis, 1989).

The experimental models can be divided into two broad classes: (1) acute inflammatory models and (2) chronic inflammatory models. Acute models are designed to test drugs that modulate blood flow (erythema), changes in vascular permeability, leukocyte migration and chemotaxis, phagocytosis - PMNLs and other phagocytic cells, measurement of local pain, antipyretic activity, local analgesic action and rat paw edema. Chronic models are designed to find drugs that may modulate the disease process and these include sponge and pellet implants and granuloma pouches which deposit granulation tissue, adjuvant induced arthritis and rabbit monoarticular arthritis which have an immune etiology (Lewis, 1989).

Experimental inflammation in whole animal is the usual starting point for anti-inflammatory testing. These experiments are varied and widely used, specially the rat paw edema test. It can be adapted in numerous ways using different inflammatory agents in attempt to mimic pathological inflammation and arthritis (Willianson, 1996).

It has been demonstrated numerous physiological changes that find a parallel in human disorders such as different forms of arthritis and acute inflammation. These responses to inflammation include variation in temperature, leukocyte counting, sedimentation rate.

Natural products have long been recognized as an important source of therapeutically effective medicines. Of the 520 new drugs approved between 1983 and 1994, $39 \%$ were natural products or derived from natural products and $60-80 \%$ of antibacterial and anticancer drugs were also derived from natural products (Cragg et al., 1997). Plants offer a vast source of compounds that present different effects in human.

The alkaloids comprise the largest single class of secondary plant substances. They have a remarkable range of pharmacological activity. The term alkaloids generally include those basic substances that contain one or more nitrogen atoms, usually in combination as part of a ciclic system (Harborne, 1991). They are often toxic to man and many have dramatic physiological activities.

Different approaches used to analyze the anti-inflammatory potential of plant and plant-derived compounds have been developed in the past years (Mascolo, 1987; Alcaraz; Jiménez, 1988; Handa et al., 1992; Gorzalczany et al., 1996, Falcão et al., 2005). In this work we review specially the alkaloids isolated and identified from the plants, previously demonstrated to have an anti-inflammatory activity. These compounds have been selected, classified in appropriate subgroups and the data are reported based on their pharmacological activity in different experimental models.

\section{MATERIAL AND METHODS}

The keywords used for this review were antiinflammatory activity plus alkaloids. The search was done using Chemical Abstracts, Biological Abstracts and in the data bank of University of Illinois in Chicago NAPRALERT (Acronym for NAtural PRoducts ALERT), updated until December 2000. The references found in the search were later consulted.

\section{RESULTS AND DISCUSSION}

Alkaloids are most common in flowering plants, and usually in the Papaveraceae (poppies), Papilonaceae (lupins), Ranunculaceae (aconites), and Solanaceae (tobacco and potatoes). They are also found in lower plants, insects, marine organisms, microorganisms and animals (Lewis, 1989).

The pharmacological studies in alkaloids have been largely concerned with the effect of alkaloids on physiological processes other than inflammation.

Only one alkaloid, colchicine is an established clinical agent for arthritic disease and leukocytoclastic vasculitis (Sais et al., 1995). The alkaloid is present in corns and seeds of crocuslike plants. Colchicine is best known for its preventive action against gout, but it also reduces pain and swelling in degenerative and immunological inflammatory disease (Malkinson, 1982).

Isoquinoline, indole and diterpene alkaloids were the most studied about their activities on inflammation. Aconitine and others alkaloids from Aconitum genus were screened for anti-inflammatory activity. They were effective on different assays including carrageenin-induced paw o edema, adjuvant-induced 
arthritis and acetic acid induced vascular permeability tests (Benn; Jacyno, 1983; Luo et al., 1991; Zhang et al., 1982; Hikino et al., 1982; Saito et al., 1982). There are about 500 species of Aconitum and the species has been intensively investigated for the pharmacological activity of their alkaloids. Since anti-rheumatic properties have been associated with this plant, some attention has been made to the anti-inflammatory activity of alkaloids in Aconitum (Lewis, 1989).

Several isoquinoline alkaloids (berbamine, berberine, cepharanthine and tetrandine) were examined for anti-inflammatory activity. They showed to be active in different assays as reported by different authors (Wong et al., 1992; Yasukawa et al., 1993; Ono, 1994; Hikino et al., 1980). For instance, tetrandrine, a bisbenzylisoquinoline alkaloid extracted from the root of the creeper Stephania tetrandra S. Moore (Menispermaceae) has been shown to inhibit neutrophil and monocyte functions, including adherence, locomotion and superoxide generation (Seow et al., 1986; Seow et al., 1988) and the plant has been used for the treatment of rheumatic diseases, silicosis and other chronic inflammatory disease (Binggi et al., 1983). Several studies showed that the alkaloid suppress antigen and mitogen-induced lymphocyte proliferation, naturalKiller cell cytotoxicity, histamine release by mast cells, interleukin-1 (IL-1) secretion by human monocytes and the action of PAF on platelets (Seow et al., 1989). Teh et al. (1989 and 1990) showed that tetrandine and its natural analogue, berbamine inhibit prostaglandin and leukotriene generation by human monocytes and neutrophils in dosedependent manner.

Berbarine is a major compound present in Phellodendri cortex and Coptidis rhizoma and the plant has been used for the treatment of diarrhea and other gastrointestinal disease in Japan and some Eastern countries. Ivanovsk; Philipov (1996) and Yasukawa et al. (1991) showed berbarine had an inhibitory effect on the ear TPA-induced inflammation indicating that this alkaloid may have important activity in chronic inflammation.

The alkaloids tend to be rather toxic, although the toxicity appears to be well below the therapeutic levels. The alkaloids appear to offer the considerable promise for further investigation as anti-inflammatory compounds, and some appears to be remarkably active.

Of the 171 evaluated alkaloids, 137 presented anti-inflammatory activity, and among those, the isoquinoline type was the most studied. The Carrageenininduced pedal edema was the most used model for evaluating the anti-inflammatory activity. In this review, 174 references were cited.

\section{ACKNOWLEDGEMENTS}

The authors wish to express their sincere thanks to College of Pharmacy, The University of Illinois at Chicago, Chicago, Illinois 60612-7231, U.S.A., for helping with the computer aided NAPRALERT search of antiinflammatory activity.

\section{REFERENCES}

Akhter MH, Sabir M, Bhide NK 1977. Anti-inflammatory effect of berberine in rats injected locally with cholera toxin. Indian J Med Res 65: 133-135.

Alcaraz MJ, Jiménez MJ 1988. Flavonoids as anti-inflammatory agents. Fitoterapia 59: 25-38.

Alkiewicz J 1983. Clinical evaluation of an aerosol medicinal plant preparation in vibratory therapy of maxillaris sinusitis of children. Herba Pol 29: 281-286.

Anonymous 1974. Antipyretic anti-inflammatory and analgesic medicine. Patent-Fr Demande-2,215,218, apud Chemical Abstracts 83: 65461.

Apoyan NA, Tumadzhyan AE, Chilingaryan DG, MelikGuseinov VV, Mnatsakanyan VA, Murav'eva DA 1984. Anti-inflammatory properties of oridine hydrochloride. Biol Zh Arm 37: 603-605, apud Chemical Abstracts 101: 183650.

Arens H, Fischer H, Leyck S, Romer A, Ulbrich B 1985. Antiinflammatory compounds from Plagiorhegma dubium cell culture. Planta Med 51: 52-56.

Backhouse N, Delporte C, Givernau M, Cassels BK, Valenzuela A, Speisky H 1994. Anti-inflammatory and antipyretic effects of boldine. Agents Actions 42: 114-117.

Bamgbose SOA, Noamesi BK 1981. Studies on cryptolepine. Planta Med 41: 392-396.

Barik BR, Bhowmik T, Dey AK, Patra A, Chatterjee A, Joy S, Susan T, Alam M, Kundu AB 1992. Premnazole, an isoxazole alkaloid of Premna integrifolia and Gmelina arborea with anti-inflammatory activity. Fitoterapia 63: 295-299.

Basu A, Lahiri SC 1977. Some pharmacological actions of solasonine. Indian J Exp Biol 15: 285-289.

Bekemeier H, Leuschner G, Schmollack W 1968. Antipyretic, antiinflammatory, and analgetic effect of damascenine. 4th Meeting Conf Hung Ther Invest Pharmacol, Soc Pharmacol Hung 449-451.

Benn MH, Jacyno JM 1983. The toxicology and pharmacology of diterpenoid alkaloids. Alkaloids: Chemical and Biological Perspectives. SW Pelletier (Ed), John Wiley \& Sons, NY v 1, 153-210.

Berezhinskaya VV 1972. New neurotropic drugs of the quinoline and isoquinoline alkaloid series. Postep Dziedzinie Leku Rosl Pr Ref Dosw Wygloszone Symp 164-171, apud Chemical Abstracts 78: 119087.

Bertelli A, Cogni G, Testi G 1956. The antipermeability effect of reserpine. Boll Soc Ital Biol Sper 32: 832.

Bhat SV, Shah V, Dohadwalla AN, Mandrekar SS, De Souza NJ 1986. Isolation of a pharmacologically active substance having the structure of a chromone alkaloid from plant(s) belonging to the Meliaceae family. Patent-Indian-157,282, apud Chemical Abstracts 106: 38467.

Binggi L, Changgi Z, Yurui L 1983. Studies on the contents of glycosaminoglycans from lungs of silicotics rats and tetrandrine treated silicotic rats. Ecotoxic Envir Safety 7: 323-329.

Birkner C, Stapel G, Leyck S, Fischer H, Christ B, Kesselring K 1986. Extraction of hopamidine. Patent-Ger Offen- 
Table 1. Alkaloids isoquinoline summary showing anti-inflammatory activity

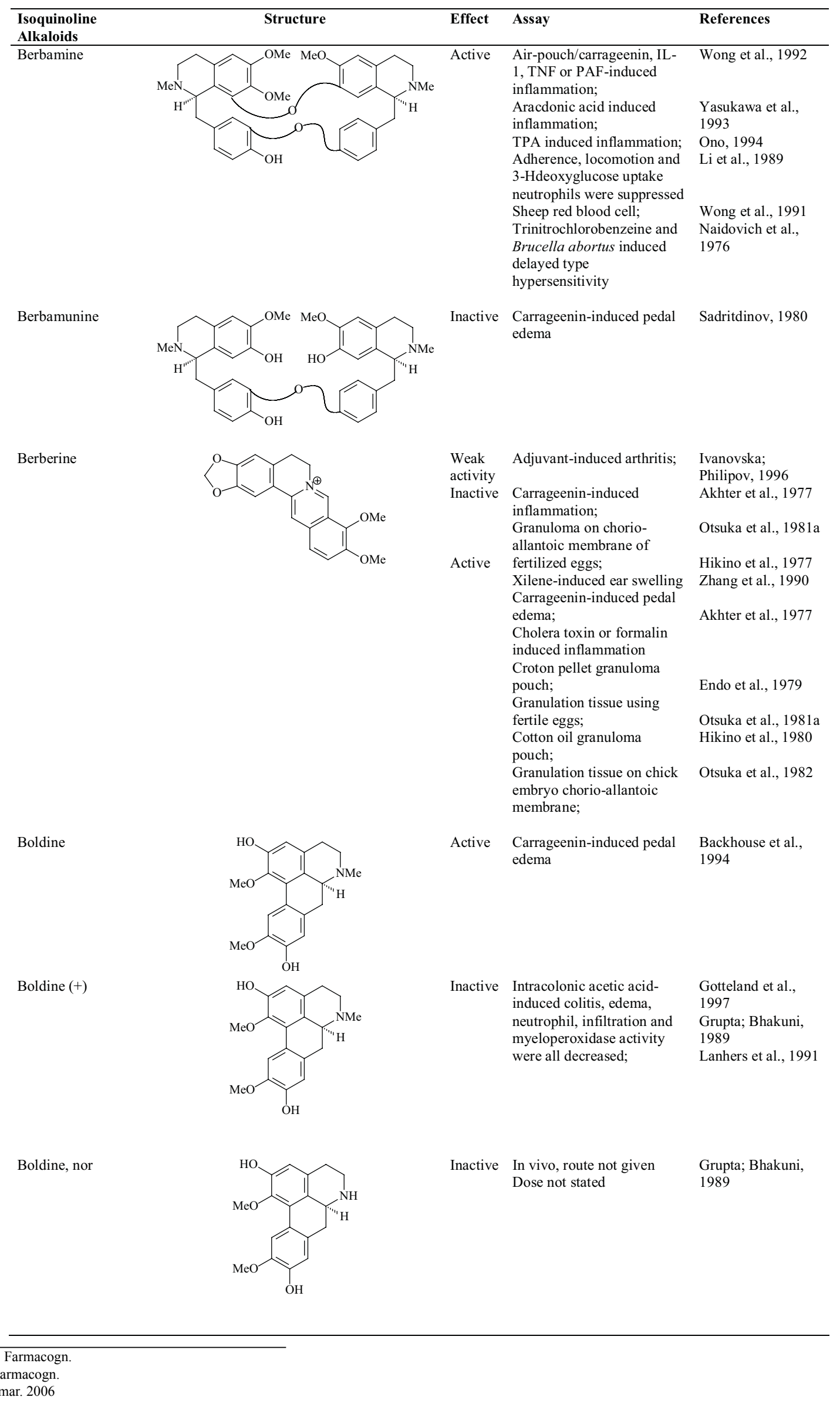




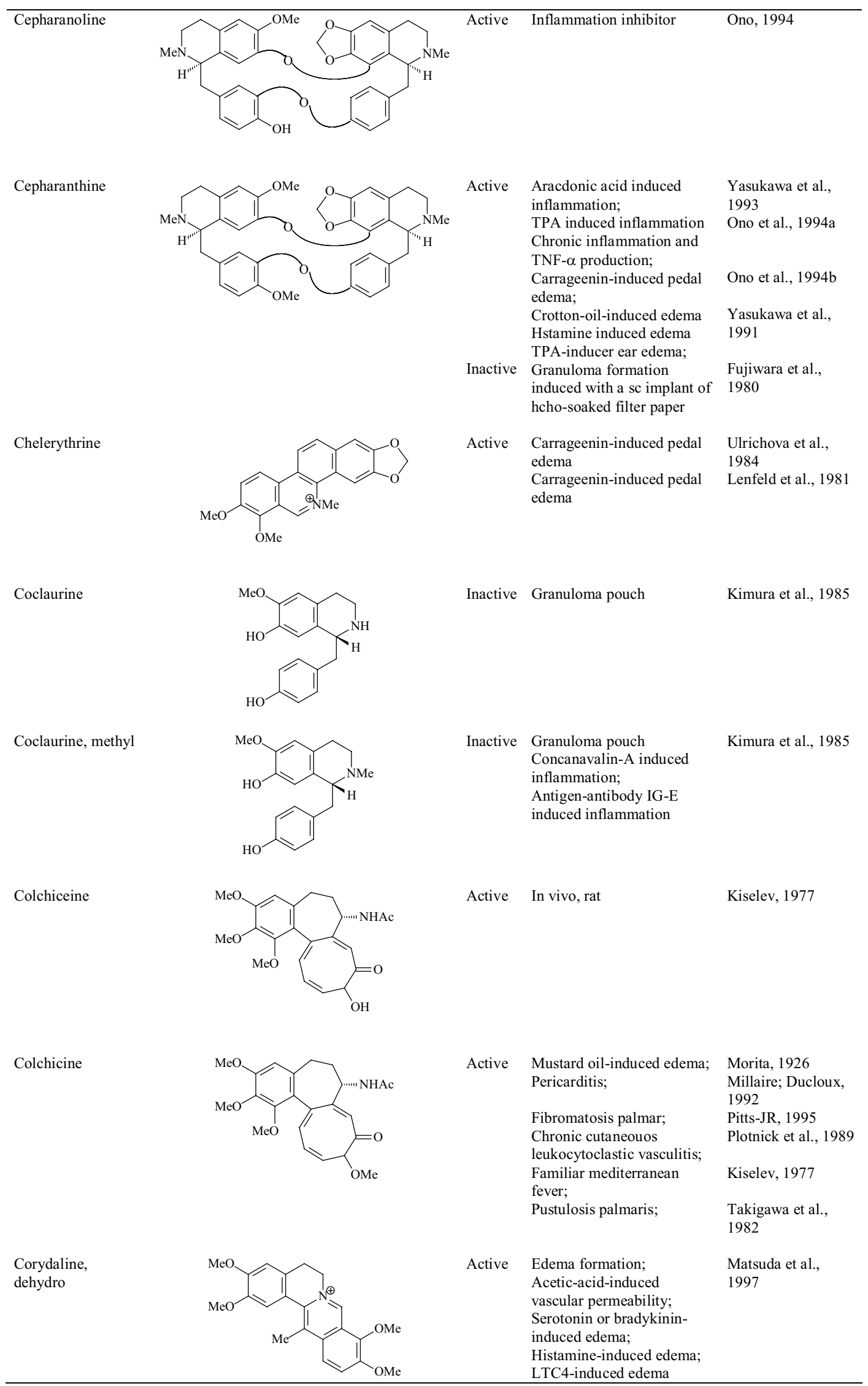



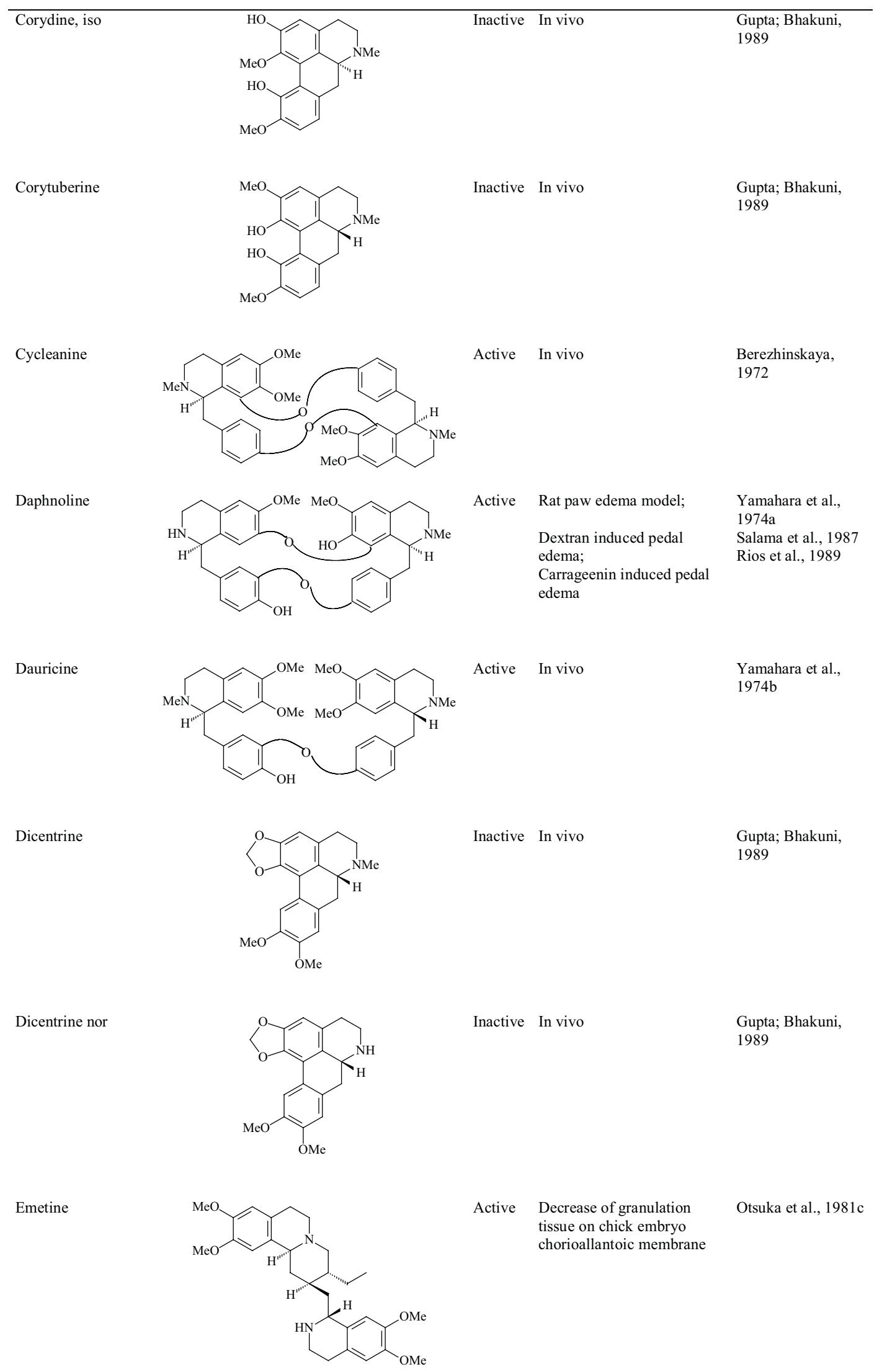


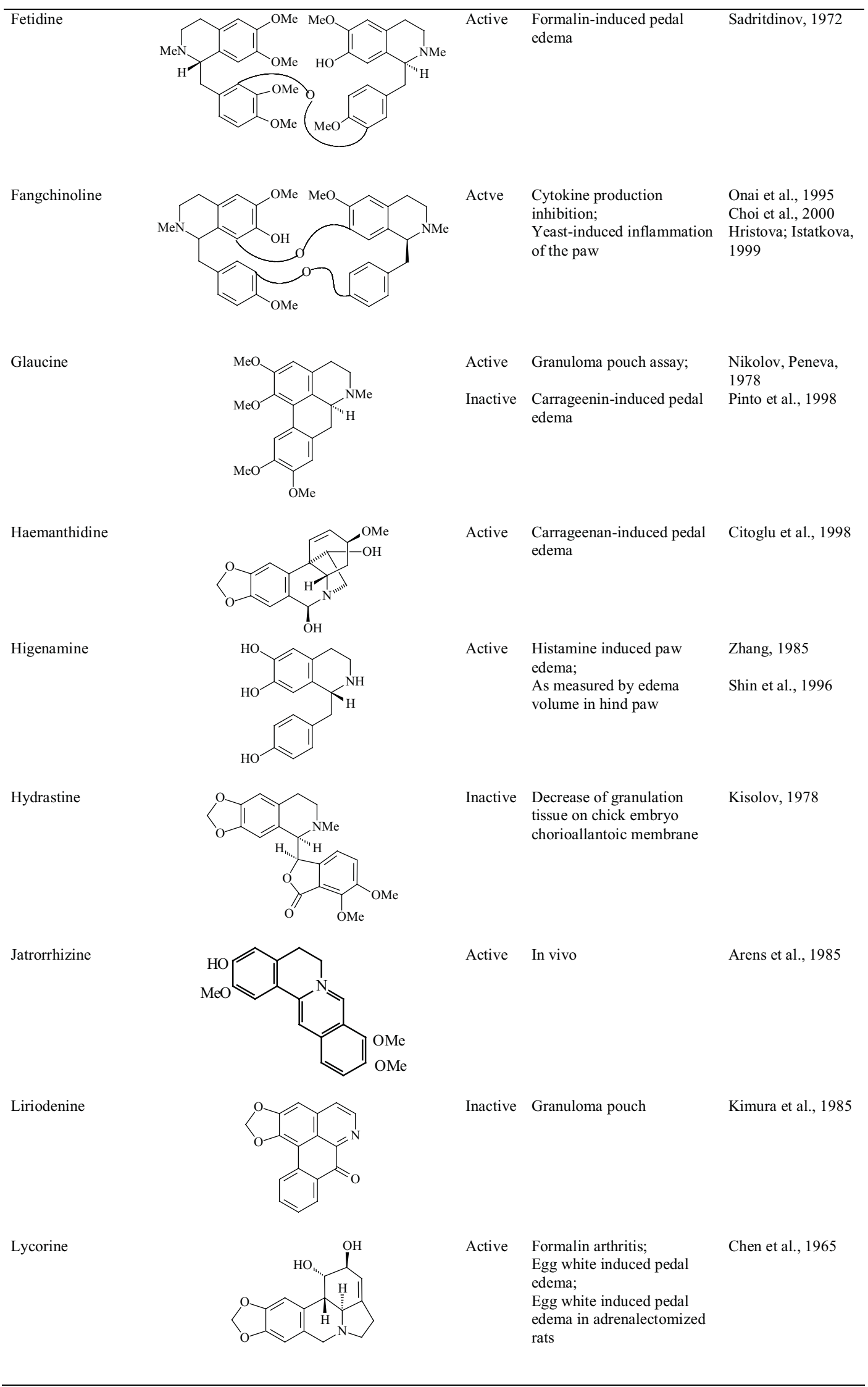

\begin{tabular}{r|r} 
& \\
\hline Rev. Bras. Farmacogn. & 115 \\
Braz J. Pharmacogn. \\
16(1):jan/mar. 2006
\end{tabular}




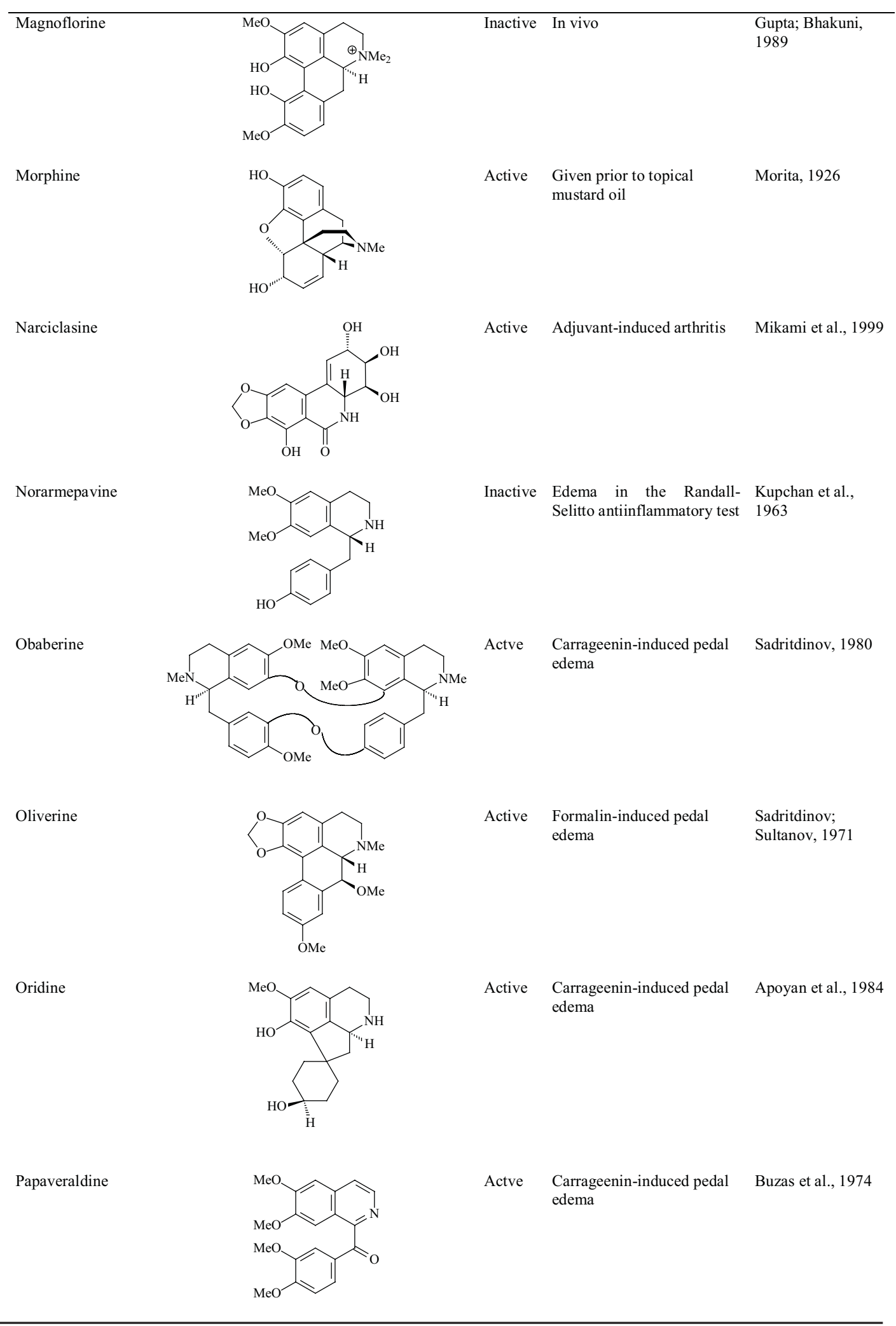




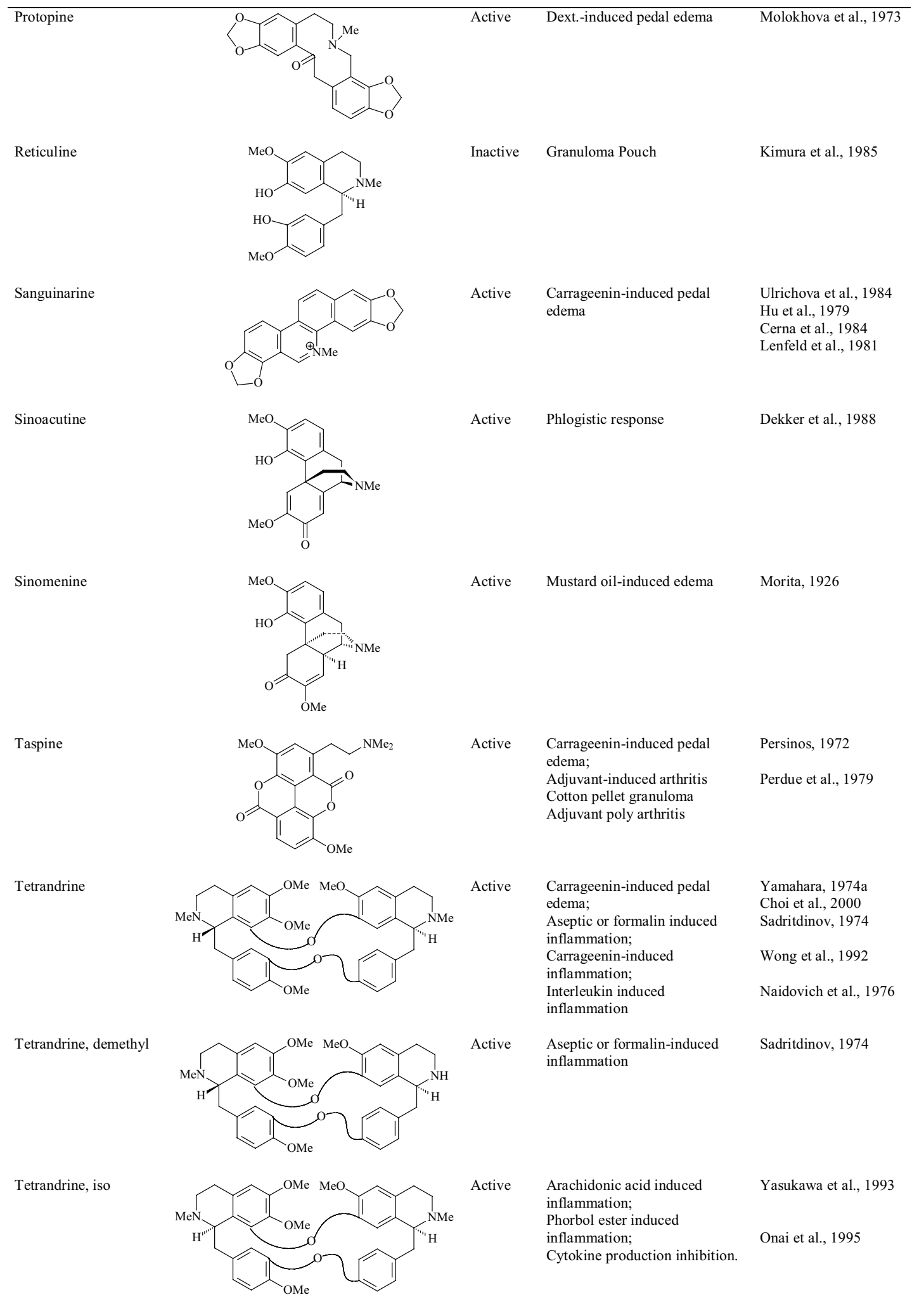

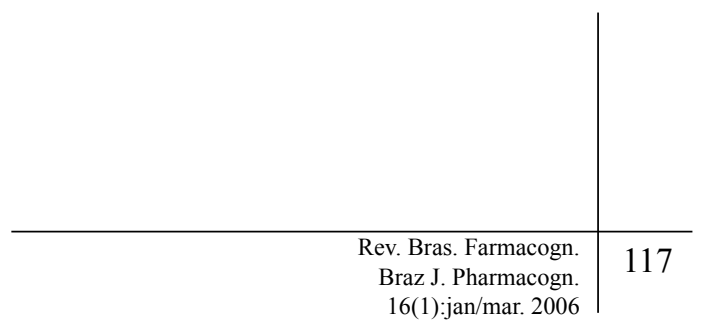




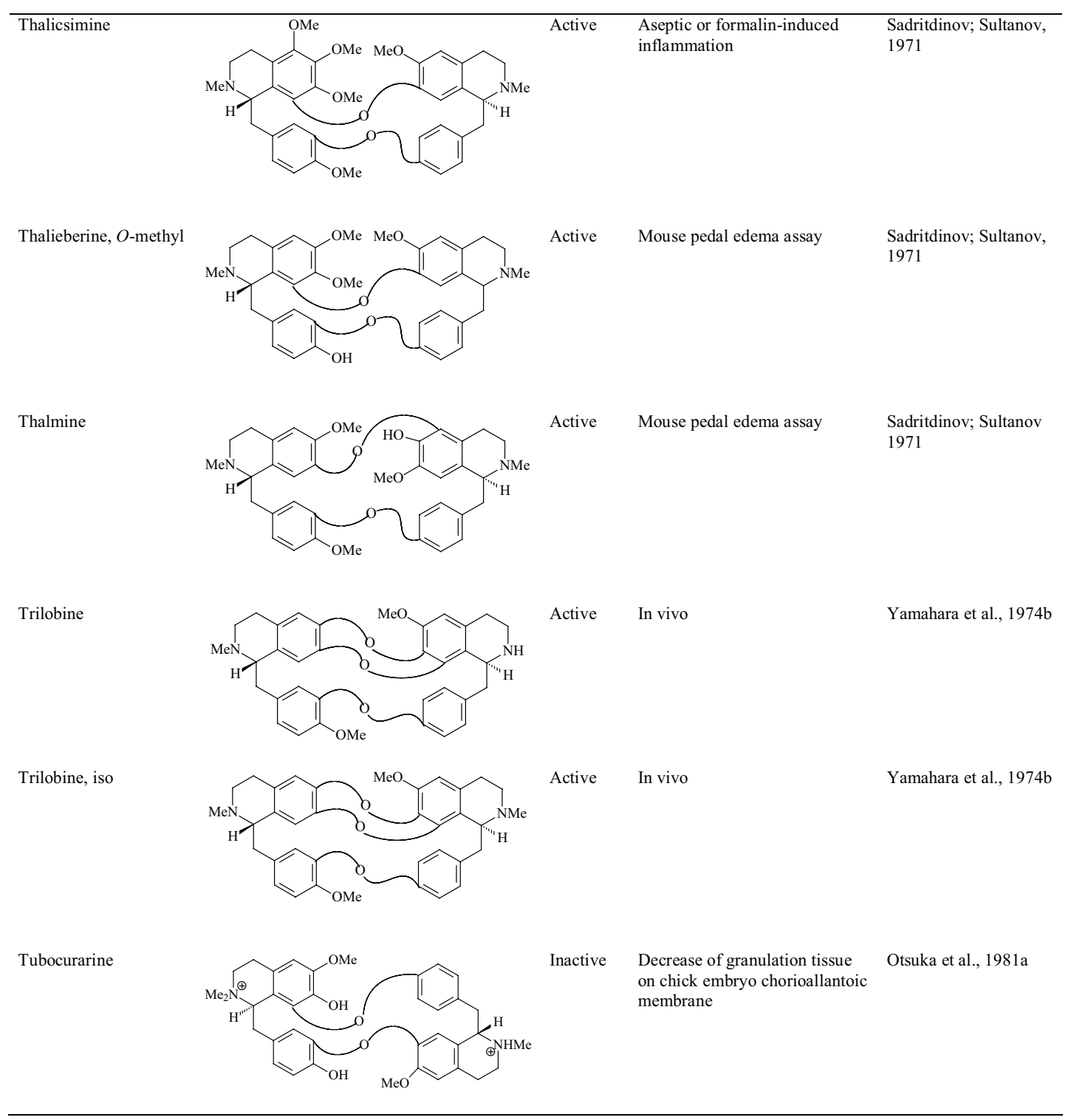


Table 2. Alkaloids indole summary showing anti-inflammatory activity

\begin{tabular}{|c|c|c|c|c|}
\hline Indole Alkaloids & Structure & Effect & Assay & References \\
\hline Ajmaline & & Active & $\begin{array}{l}\text { Carrageenin-induced pedal } \\
\text { edema }\end{array}$ & Saeed et al., 1993 \\
\hline $\begin{array}{l}\text { Alstonine, } \\
\text { tetrahydro }\end{array}$ & $\stackrel{\mathrm{H}}{=}$ & $\begin{array}{l}\text { Week } \\
\text { activity }\end{array}$ & $\begin{array}{l}\text { Carrageenan-induced pedal } \\
\text { edema }\end{array}$ & Kocislski et al., 1972 \\
\hline Annomontine & & Active & In vivo & Leboeuf et al., 1982 \\
\hline $\begin{array}{l}\text { Annomontine, } \\
\text { methoxy }\end{array}$ & & Active & In vivo & Lebouef et al., 1982 \\
\hline Brucine & & Inactive & $\begin{array}{l}\text { Carrageenin-induced pedal } \\
\text { edema }\end{array}$ & Tits et al., 1991 \\
\hline Cryptolepine & & Active & $\begin{array}{l}\text { Carrageenin-induced pedal } \\
\text { edema }\end{array}$ & $\begin{array}{l}\text { Noamesi; Bamgbose, } \\
1983 \\
\text { Bamgbose; Noamesi, } \\
1981\end{array}$ \\
\hline Evodiamine & & Active & $\begin{array}{l}\text { Carrageenan-induced pedal } \\
\text { edema; } \\
\text { Serotonin induced edema; } \\
\text { Bradykinin-induced edema; } \\
\text { Arachidonic acid-induced } \\
\text { ear swelling }\end{array}$ & Matsuda et al., 1998 \\
\hline Holstiine & & Inactive & $\begin{array}{l}\text { Carrageenin-induced pedal } \\
\text { edema }\end{array}$ & $\begin{array}{l}\text { Bamgbose; Noamesi, } \\
1981 \\
\text { Tits et al., } 1991\end{array}$ \\
\hline Melatonin & & Active & $\begin{array}{l}\text { Carrageenin-induced pedal } \\
\text { edema }\end{array}$ & Mimura et al., 1982 \\
\hline
\end{tabular}




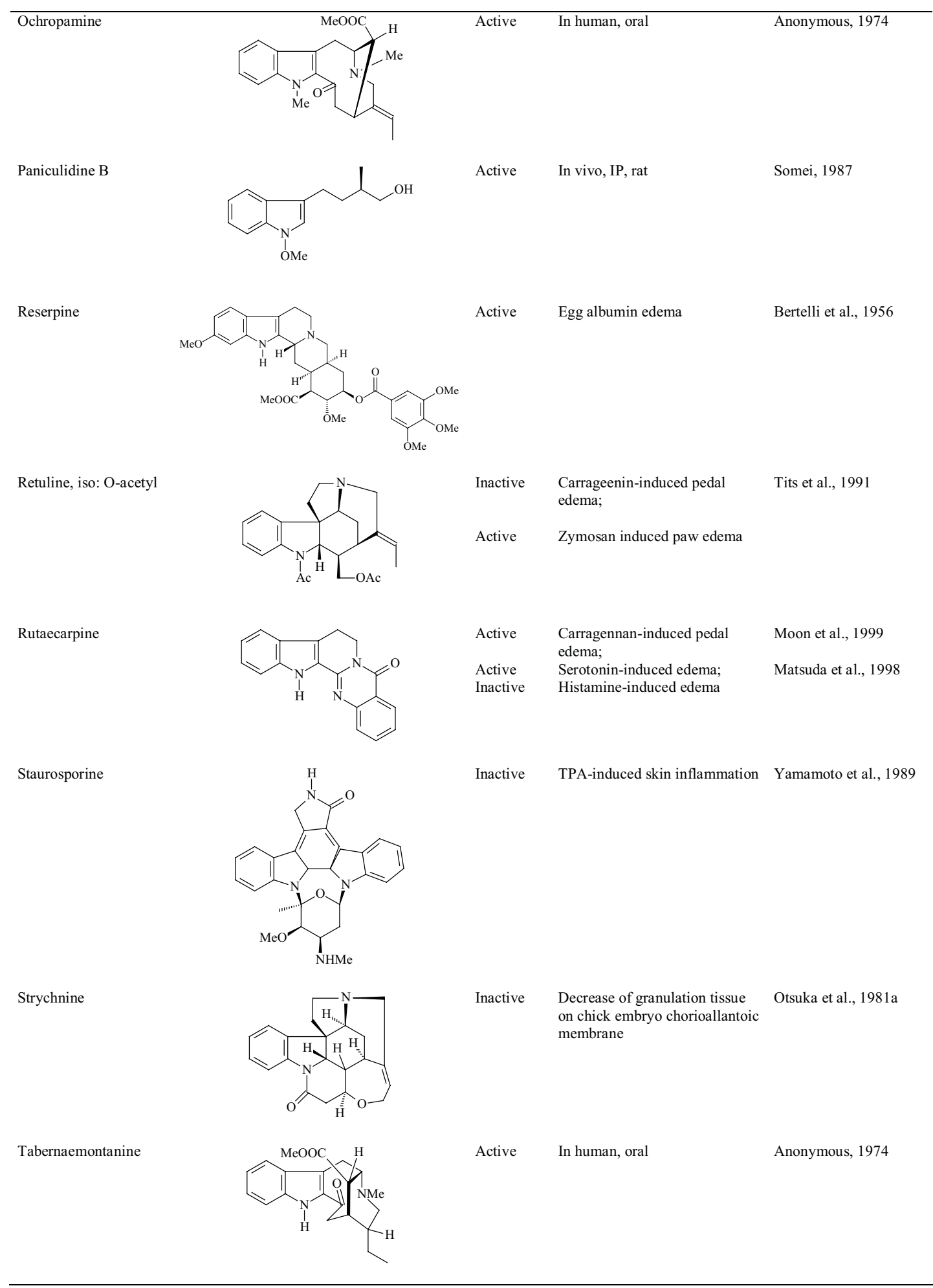




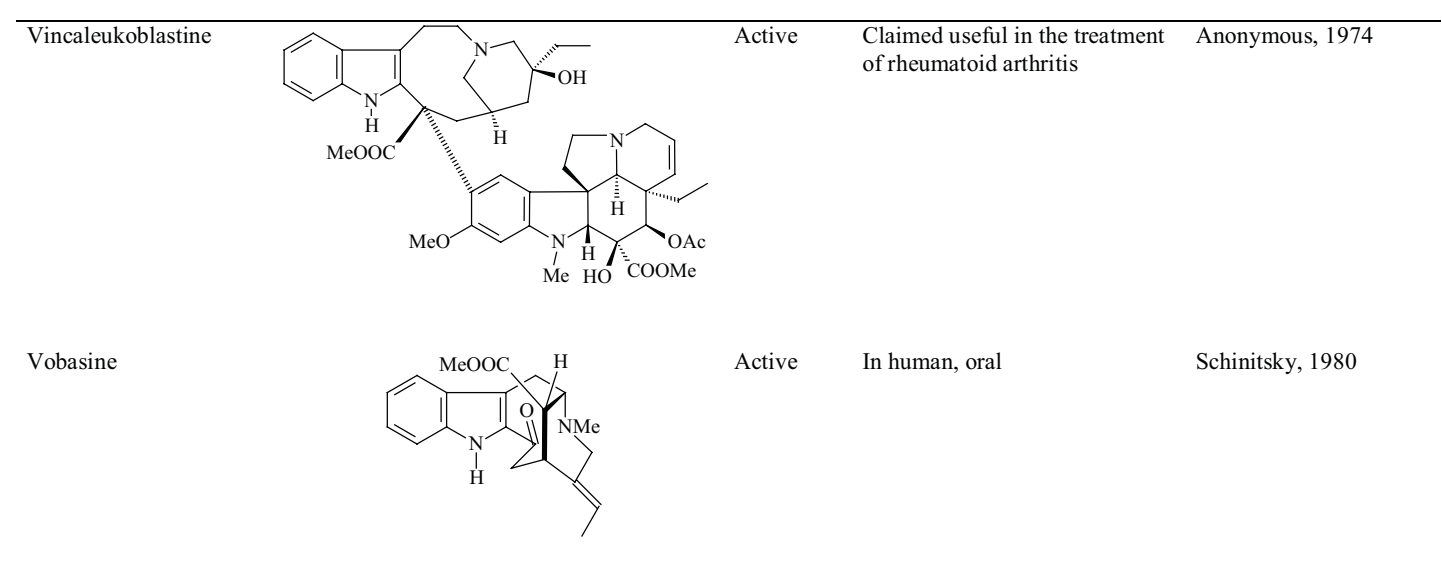


Table 3. Alkaloids diterpene summary showing anti-inflammatory activity

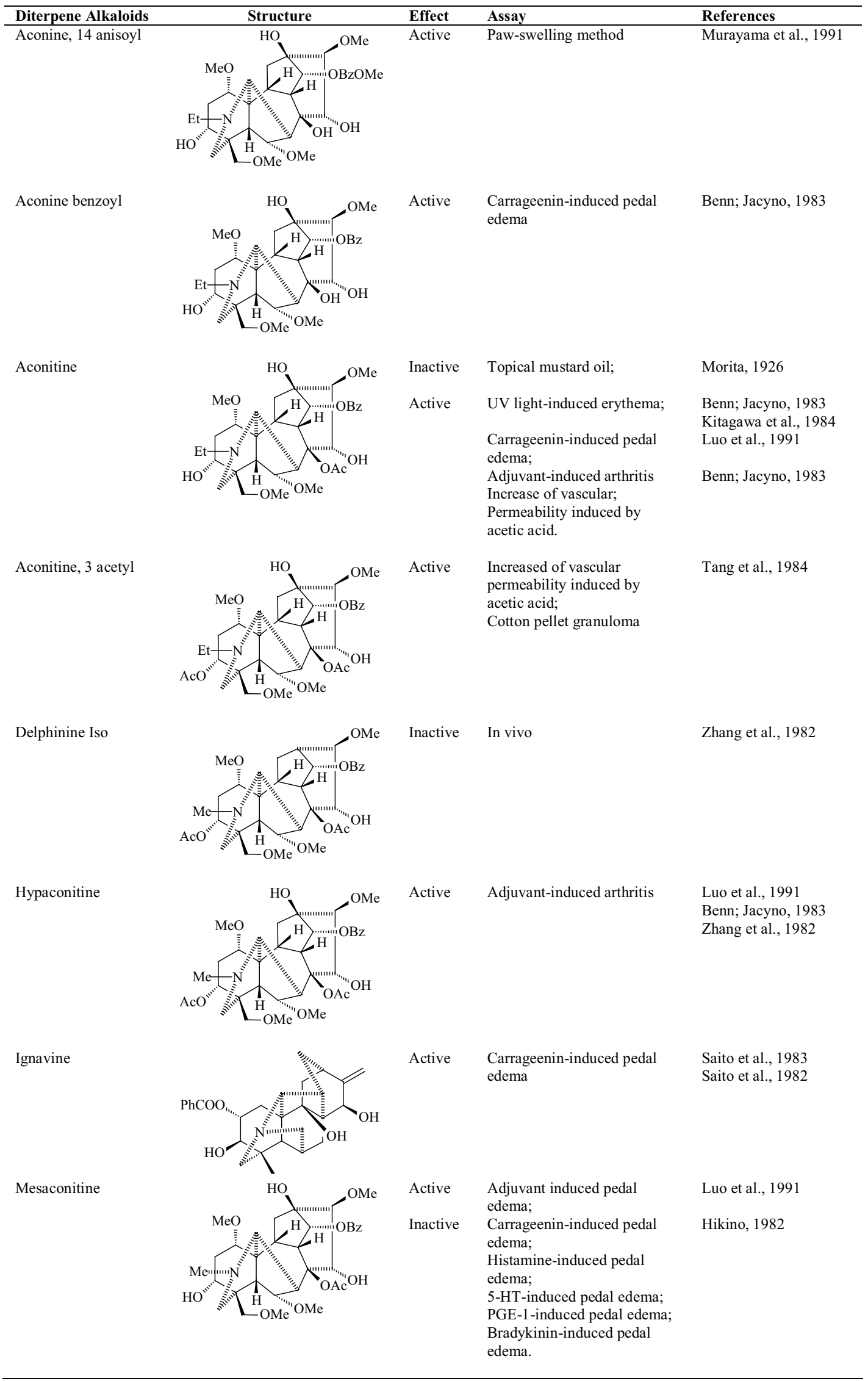




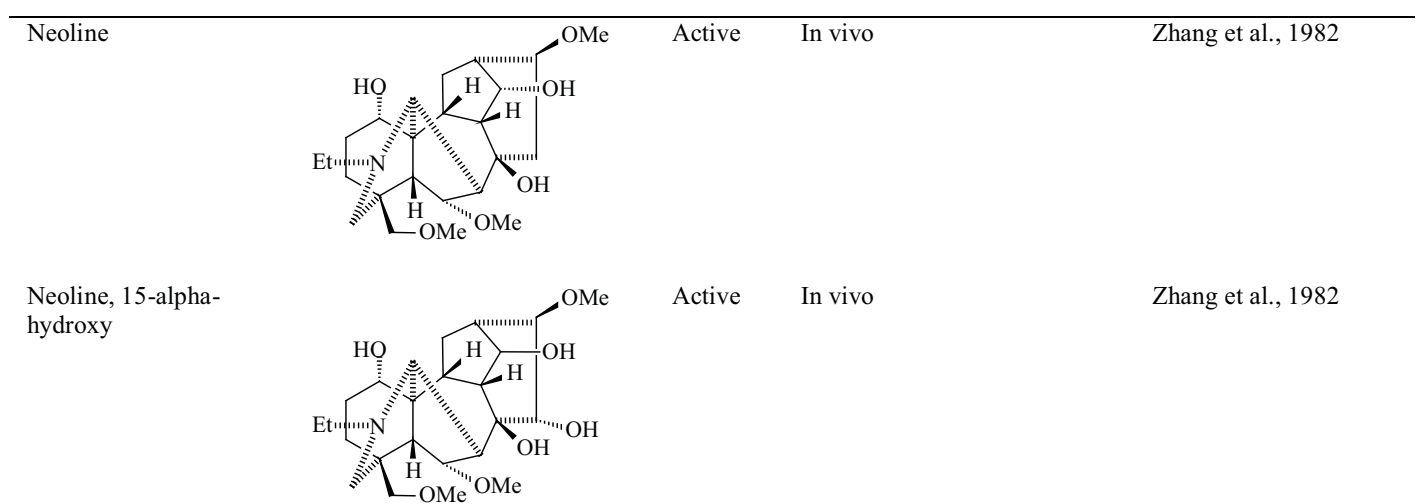

Pyroaconitine

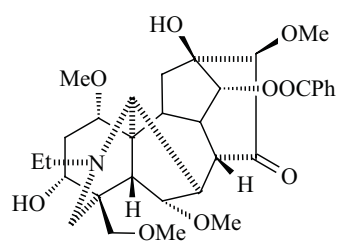
Active Carrageenin-induced pedal edema
Murayama et al., 1991

Pyroaconitine, 16 epi

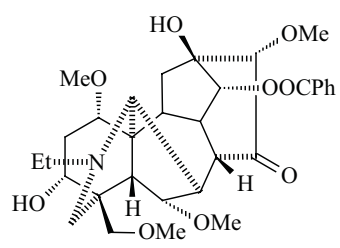

Active

Carrageenin-induced pedal edema

Murayama et al., 1991

Pyrohypaconitine

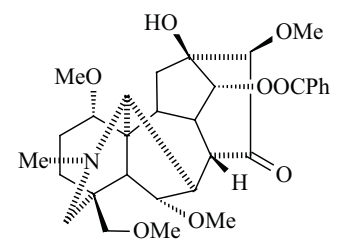

Active Carrageenin-induced pedal edema

Murayama et al., 1991

Pyrojesaconitine

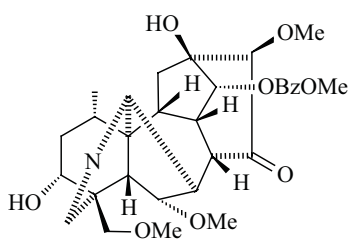

Active

Carrageenin-induced pedal edema

Murayama et al., 1991

Pyrojesaconitine, 16

epi

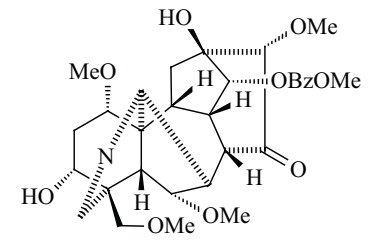

Active Carrageenin-induced pedal edema

Murayama et al., 1991

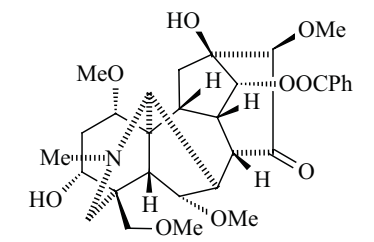

Active

Carrageenin-induced pedal edema

Murayama et al., 1991

Pyromesaconitine 
José M. Barbosa-Filho, Márcia R. Piuvezam, Marcelo D. Moura, et al.

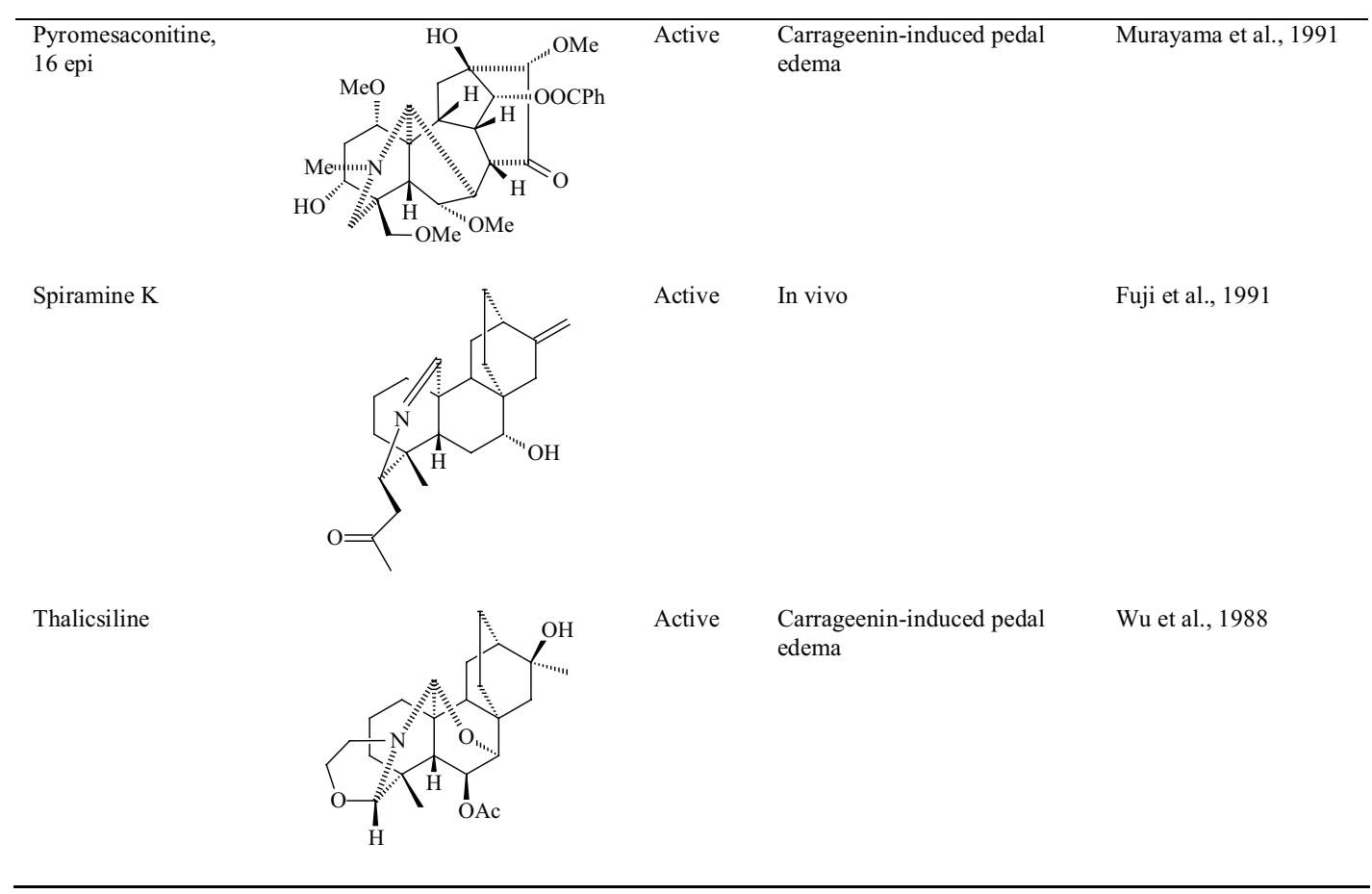


Table 4. Alkaloids steroid summary showing anti-inflammatory activity

\begin{tabular}{lllll}
\hline Steroid Alkaloids & Structure & Effect & Assay & References \\
\hline Cevadine & $\begin{array}{l}\text { Topical mustard-oil } \\
\text { Endotoxin induced posterior } \\
\text { uveitis }\end{array}$ & Morita, 1926 \\
\hline
\end{tabular}

Cyclobuxine D<smiles>C=C1C(NC)CCC23CC4CCC5(C)C(CC(O)C5[C@H](C)NC)C4CCC2C13C</smiles>

Edpetiline

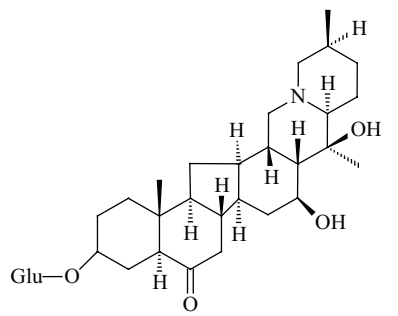

Funtumidine<smiles>CC(O)C1CCC2C3CCC4C[C@H](N)CCC4(C)C3CCC12C</smiles>

Funtumine<smiles>CC(=O)C1CCC2C3CCC4CC(N)CCC4(C)C3CCC12C</smiles>

Gitingensine<smiles>CC1OC(=O)C23CCC4C(CC=C5CC(N)CCC54C)C2(C)CCC1[C@H]3C</smiles><smiles>CC(=O)C1CCC2C3CC=C4CC(N)CCC4(C)C3CCC12C</smiles>

\section{Holamine}

Inactive

\section{Histamine-induced} ventilation overflow

Active Not specified

Active

Active

Kaolin-induced

inflammation;

Egg albumin induced inflammation

Edema in the rat's paw

Edema in the rat's paw

Blanpin;

Quevauviller, 1960

Estrada et al., 1966

Oletta, 1964

Oletta, 1964

\section{Holaphyllamine}<smiles>CC(=O)C1CCC2C3CC=C4CC(N)CCC4(C)C3CCC12C</smiles> 
Holaphylline<smiles>CNC1CCC2C(=CCC3C2(C)CCC2C4CCC(C(C)=O)C4(C)C23C)C1</smiles>

Petiline<smiles></smiles>

Active

Active

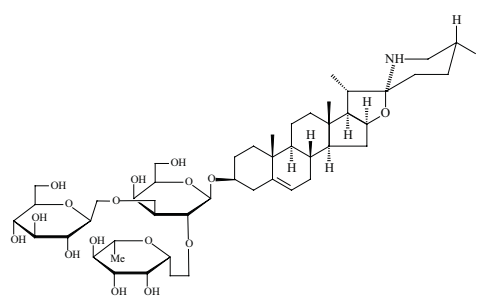

Tomatine

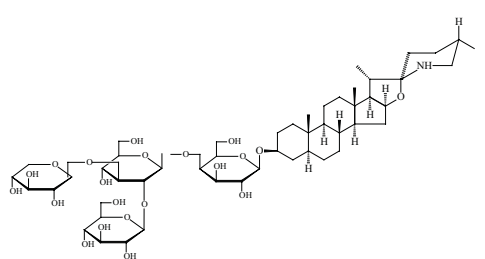

Veralosine

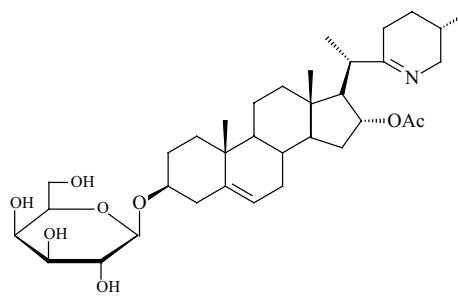

Egg albumin induced

inflammation;

Kaolin-induced

inflammation

Oletta, 1964

Saidkasimov et al., 1971

Cotton pellet granuloma Carrageenin-induced pedal edema

Carrageenan induced paw edema;

Filderman; Kovacs, 1969

Granulation tissue

formation induced by the s.c. implantation of carrageenan impregnated cotton pellets;

I.p. injection of acidified saline and i.v. pontamine sky blue

Basu; Lahiri, 1977

In vivo, rat

Saidkasymov, 1978 
Table 5. Alkaloids amide summary showing anti-inflammatory activity

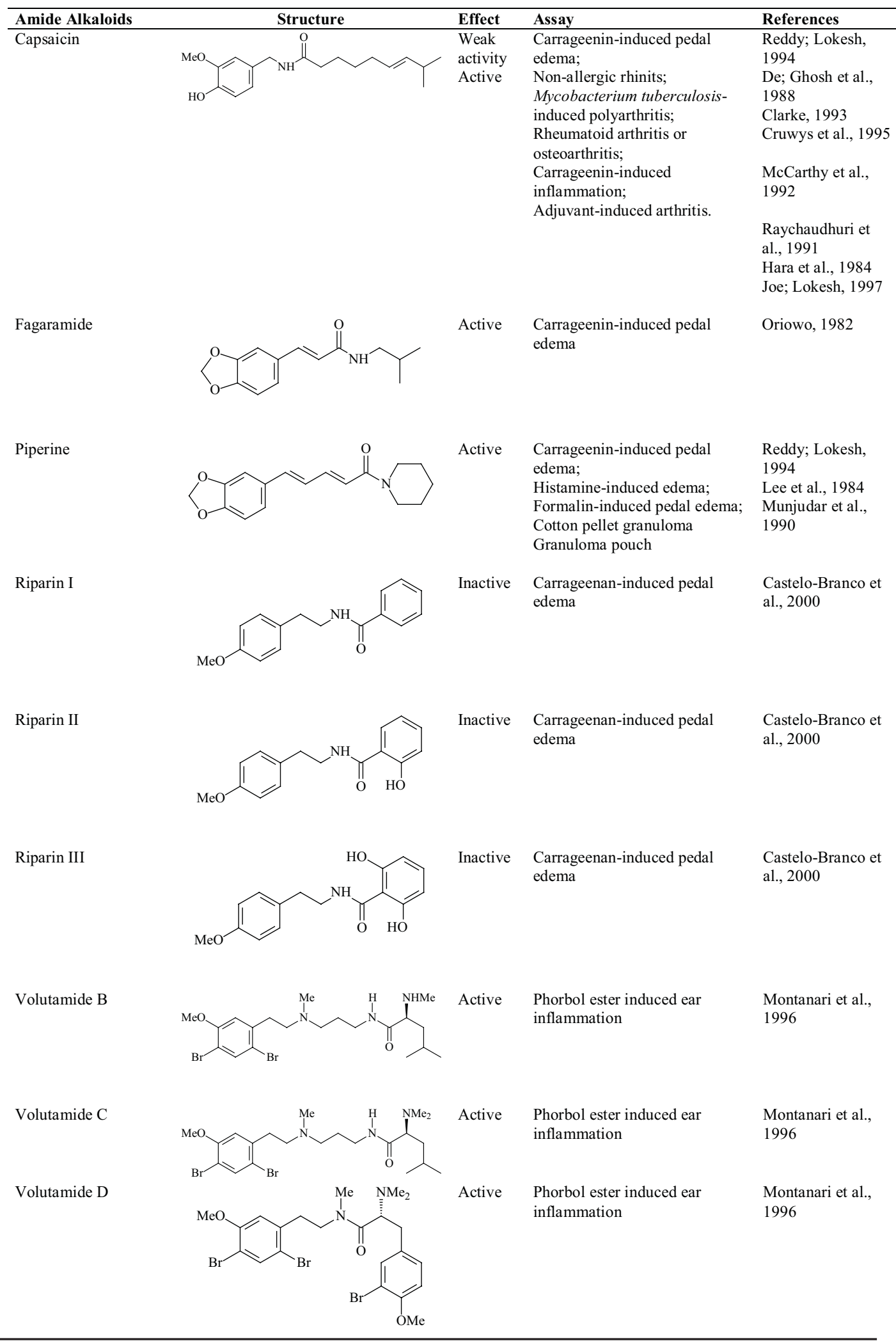


Table 6. Alkaloids quinolizidine summary showing anti-inflammatory activity

\begin{tabular}{|c|c|c|c|c|}
\hline $\begin{array}{l}\text { Quinolizidine } \\
\text { Alkaloids }\end{array}$ & Structure & Effect & Assay & References \\
\hline Cryogenine & & Active & $\begin{array}{l}\text { Carrageenan-induced pedal } \\
\text { edema; } \\
\text { Chronic anti-inflammatory } \\
\text { evaluation; } \\
\text { Adjuvant-induced arthrits }\end{array}$ & $\begin{array}{l}\text { Kocialski et al., } 1972 \\
\text { Kaplan et al., } 1967\end{array}$ \\
\hline Lupanine, 17 oxo & & Active & $\begin{array}{l}\text { Carrageenin-induced pedal } \\
\text { edema }\end{array}$ & Murakoshi et al., 1992 \\
\hline Lythrine & & Active & $\begin{array}{l}\text { Carragenin-induced pedal } \\
\text { edema }\end{array}$ & Byrne; Malone, 1981 \\
\hline Matrine & & Active & Decrease ear inflammation & Tan; Zhang, 1985 \\
\hline Matrine, oxy & & Active & In vivo, rat & Ma et al., 1991 \\
\hline Nesodine & & Active & Active & Handa et al., 1992 \\
\hline Sparteine & & Active & Croton-oil induced edema & Chang, Malone, 1971 \\
\hline
\end{tabular}


Table 7. Alkaloids quinoline summary showing anti-inflammatory activity

\begin{tabular}{|c|c|c|c|c|}
\hline Quinoline Alkaloids & Structure & Effect & Assay & References \\
\hline Acronycidine & $\mathrm{OMe} \mathrm{OMe}$ & Inactive & Erythema block & $\begin{array}{l}\text { Svoboda; Kattau, } \\
1967\end{array}$ \\
\hline Cinchonine & & Active & Mustard oil-induced edema & Morita, 1926 \\
\hline Quinidine & & Active & Mustard oil-induced edema & Morita, 1926 \\
\hline Quinine & & Active & $\begin{array}{l}\text { Mustard oil-induced edema; } \\
\text { Decrease of granulation tissue on } \\
\text { chick embryo chorioallantoic } \\
\text { membrane; } \\
\text { Carrageenan-induced pedal } \\
\text { edema }\end{array}$ & $\begin{array}{l}\text { Morita, } 1926 \\
\text { Otsuka et al., 1981b }\end{array}$ \\
\hline Skimmianine & & Active & TPA-induced inflammation & $\begin{array}{l}\text { Garcia-Argaez et al., } \\
2000\end{array}$ \\
\hline
\end{tabular}


Table 8. Alkaloids purine summary showing anti-inflammatory activity

\begin{tabular}{|c|c|c|c|c|}
\hline Purine Alkaloids & Structure & Effect & Assay & References \\
\hline Adenine & $\mathrm{NH}_{2}$ & Inactive & Fertille egg method & Otsuka et al., 1974 \\
\hline Adenosine & & Active & $\begin{array}{l}\text { Inhibited TNF } \alpha \text { mediated } \\
\text { inflammation responses }\end{array}$ & Parmely et al., 1993 \\
\hline Caffeine & & $\begin{array}{l}\text { Active } \\
\text { Inactive }\end{array}$ & $\begin{array}{l}\text { Phorbol acetate induced edema; } \\
\text { Formalin-induced pedal edema. }\end{array}$ & Yasukawa et al., 1991 \\
\hline Theophylline & & Active & $\begin{array}{l}\text { Adjuvant-induced arthritis; } \\
\text { Dextran-induced pedal edema; } \\
\text { Carrageenin-induced pedal } \\
\text { edema }\end{array}$ & $\begin{array}{l}\text { Revesz et al., } 1992 \\
\text { Sullivan et al., } 1994\end{array}$ \\
\hline
\end{tabular}

Table 9. Alkaloids aliphatic summary showing anti-inflammatory activity

\begin{tabular}{|c|c|c|c|c|}
\hline $\begin{array}{l}\text { Aliphatic } \\
\text { Alkaloids }\end{array}$ & Structure & Effect & Assay & References \\
\hline Desferrioxamine & $\begin{array}{c}\mathrm{H}_{2} \mathrm{~N}\left(\mathrm{CH}_{2}\right)_{5} \mathrm{~N}(\mathrm{OH}) \mathrm{CO}\left(\mathrm{CH}_{2}\right)_{2} \mathrm{CONH}\left(\mathrm{CH}_{2}\right)_{5} \mathrm{~N}(\mathrm{OH}) \\
\mathrm{Ac}(\mathrm{OH}) \mathrm{N}\left(\mathrm{CH}_{2}\right)_{5} \mathrm{NHCO}\left(\mathrm{CH}_{2}\right)_{5} \mathrm{CO}\end{array}$ & Active & Antigen-induced inflammation & $\begin{array}{l}\text { Yoshino et al., } \\
1984\end{array}$ \\
\hline Putrescine & $\mathrm{H}_{2} \mathrm{NCH}_{2} \mathrm{CH}_{2} \mathrm{CH}_{2} \mathrm{CH}_{2} \mathrm{NH}_{2}$ & $\begin{array}{l}\text { Inactive } \\
\text { Active }\end{array}$ & $\begin{array}{l}\text { Effect chemotaxis; } \\
\text { Serotonin induced paw edema }\end{array}$ & $\begin{array}{l}\text { Haigh et al., } 184 \\
\text { Suzuki et al., } 1983\end{array}$ \\
\hline Spermidine & $\mathrm{H}_{2} \mathrm{~N}\left(\mathrm{CH}_{2}\right)_{3} \mathrm{NH}\left(\mathrm{CH}_{2}\right)_{4} \mathrm{NH}_{2}$ & Active & Serotonin induced pedal edema & Suzuki et al., 1983 \\
\hline Spermine & $\mathrm{H}_{2} \mathrm{~N}\left(\mathrm{CH}_{2}\right)_{3} \mathrm{NH}\left(\mathrm{CH}_{2}\right)_{4} \mathrm{NH}\left(\mathrm{CH}_{2}\right)_{3} \mathrm{NH}_{2}$ & Active & Serotonin induced pedal edema & Suzuki et al., 1983 \\
\hline
\end{tabular}


Table 10. Alkaloids monoterpene summary showing anti-inflammatory activity

\begin{tabular}{|c|c|c|c|c|}
\hline $\begin{array}{l}\text { Monoterpene } \\
\text { Alkaloids }\end{array}$ & Structure & Effect & Assay & References \\
\hline Gentianadine & & Active & In vivo, oral, rat & Sadritdinov, 1972 \\
\hline Gentianamine & & Active & Formalin-induced pedal edema & Sadritdinov, 1971 \\
\hline Gentianidine & & $\begin{array}{l}\text { Week } \\
\text { activity }\end{array}$ & Formalin-induced pedal edema & Sadritdinov, 1971 \\
\hline Gentianine & & Active & $\begin{array}{l}\text { Mouse paw edema test; } \\
\text { Formalin-induced-pedal edema; } \\
\text { Egg white-induced pedal edema }\end{array}$ & $\begin{array}{l}\text { Tulyaganov, } 1971 \\
\text { Sung et al., } 1958\end{array}$ \\
\hline
\end{tabular}

Table 11. Alkaloids pirrole summary showing anti-inflammatory activity

\begin{tabular}{|c|c|c|c|c|}
\hline Pirrole Alkaloids & Structure & Effect & Assay & References \\
\hline Ganoderma A & & Active & In vivo & Yang; Yu, 1990 \\
\hline Ganoderma B & & Active & In vivo & Yang; Yu, 1990 \\
\hline Hopamidine & $\mathrm{H}$ & Active & Cobra venom. Induced edema & Birkner et al., 1986 \\
\hline
\end{tabular}


Table 12. Alkaloids phenetylamine summary showing anti-inflammatory activity

\begin{tabular}{|c|c|c|c|c|}
\hline $\begin{array}{l}\text { Phenetylamine } \\
\text { Alkaloids }\end{array}$ & Structure & Effect & Assay & References \\
\hline Ephedrine & $\begin{array}{c}\mathrm{CH}_{3} \\
\mathrm{I} \\
\mathrm{O}-\mathrm{CH}-\mathrm{NHCH}_{3} \\
+\end{array}$ & $\begin{array}{l}\text { Active } \\
\text { Inactive }\end{array}$ & $\begin{array}{l}\text { Dinitrofluorbenzene-induced } \\
\text { swelling; } \\
\text { Carrageenin, PGE-1, histamine, } \\
\text { serotonin and bradikinin-induced } \\
\text { pedal edema; } \\
\text { Carrageenin-induced pedal } \\
\text { edema; } \\
\text { Increased vascular permeability } \\
\text { induced by acetic acid, resistence } \\
\text { of heat-induced hemolysis of rat } \\
\text { RBC, decrease of granulation } \\
\text { tissue on chick embryo chorio- } \\
\text { allantoic membrane }\end{array}$ & $\begin{array}{l}\text { Hwang et al., } 1990 \\
\text { Kasahara et al., } 1985 \\
\text { Alkiewicz, } 1983 \\
\text { Hikino et al., } 1980\end{array}$ \\
\hline Ephedrine, $N$-methyl & $\begin{array}{l}\mathrm{CH}_{3} \\
-\mathrm{CH}-\mathrm{N}\left(\mathrm{CH}_{3}\right)_{2}\end{array}$ & $\begin{array}{l}\text { Weak } \\
\text { activity }\end{array}$ & $\begin{array}{l}\text { Carrageenin-induced pedal } \\
\text { edema; } \\
\text { Resistence of heat-induced } \\
\text { hemolysis of rat RBC; } \\
\text { Effect on increased vascular } \\
\text { permeability induced by acetic } \\
\text { acid }\end{array}$ & Hikino et al., 1980 \\
\hline Ephedrine, pseudo & $\begin{array}{l}\mathrm{H} \\
\text { I } \\
-\mathrm{C}-\mathrm{NHCH}_{3} \\
\mathrm{CH}_{3}\end{array}$ & $\begin{array}{l}\text { Inactive } \\
\text { Weak } \\
\text { activity } \\
\text { Active }\end{array}$ & $\begin{array}{l}\text { Dinitrofluorbenzene-induced } \\
\text { swelling; } \\
\text { Carrageenin-induced pedal } \\
\text { edema; } \\
\text { Effect on increased vascular } \\
\text { permeability induced by acetic } \\
\text { acid; } \\
\text { Carrageenin-induced pedal } \\
\text { edema; } \\
\text { Effect on increased vascular } \\
\text { Permeability induced by acetic } \\
\text { acid; } \\
\text { Resistence of heat-induced } \\
\text { hemolysis of rat RBC; } \\
\text { Decrease of degranulation tissue } \\
\text { on chick embryo chorioallantoic } \\
\text { membrane; } \\
\text { Croton oil-induced edema }\end{array}$ & $\begin{array}{l}\text { Hwang et al., } 1990 \\
\text { Hikino et al., } 1980\end{array}$ \\
\hline
\end{tabular}

Table 13. Alkaloids piperidine summary showing anti-inflammatory activity

\begin{tabular}{|c|c|c|c|c|}
\hline Piperidine Alkaloids & Structure & Effect & Assay & references \\
\hline Arecoline & $\mathrm{Me}$ & Inactive & $\begin{array}{l}\text { Granulation tissue on chick } \\
\text { embryo chorioallantoic membrane }\end{array}$ & Otsuka et al., 1981b \\
\hline Rohitukine & & Active & Carrageenin-induced pedal edema & $\begin{array}{l}\text { Naik et al., } 1988 \\
\text { Bhat et al., } 1986 \\
\text { Lakdawala et al., } \\
1988\end{array}$ \\
\hline
\end{tabular}


Table 14. Alkaloids piridine summary showing anti-inflammatory activity

\begin{tabular}{llll}
\hline Piridine Alkaloids & Assay & $\begin{array}{l}\text { Eeferences } \\
\text { Aukhamedzhanova } \\
\text { induced pedal edema }\end{array}$ \\
\hline Anabasamine & $\begin{array}{l}\text { Active } \\
\text { Nicotine }\end{array}$ & $\begin{array}{l}\text { Decrease of granulation tissue } \\
\text { on chick embryo chorioallantoic } \\
\text { membrane }\end{array}$ & Otsuka et al., 1981a
\end{tabular}

Table 15. Alkaloids indolizidine summary showing anti-inflammatory activity

\begin{tabular}{llll}
\hline Indolizidine Alkaloids & Effect & Assay & References \\
\hline Castanospermine & $\begin{array}{l}\text { Active } \\
\text { allergic encephalomyelitis }\end{array}$ & Willenborg et al., 1990 \\
Tylophorine & Active & $\begin{array}{l}\text { Granuloma pouch assay; } \\
\text { Cotton pellet granuloma }\end{array}$ & $\begin{array}{c}\text { Gopalakrishnan et al., } \\
1979\end{array}$ \\
\hline
\end{tabular}

Table 16. Alkaloids tropane summary showing anti-inflammatory activity

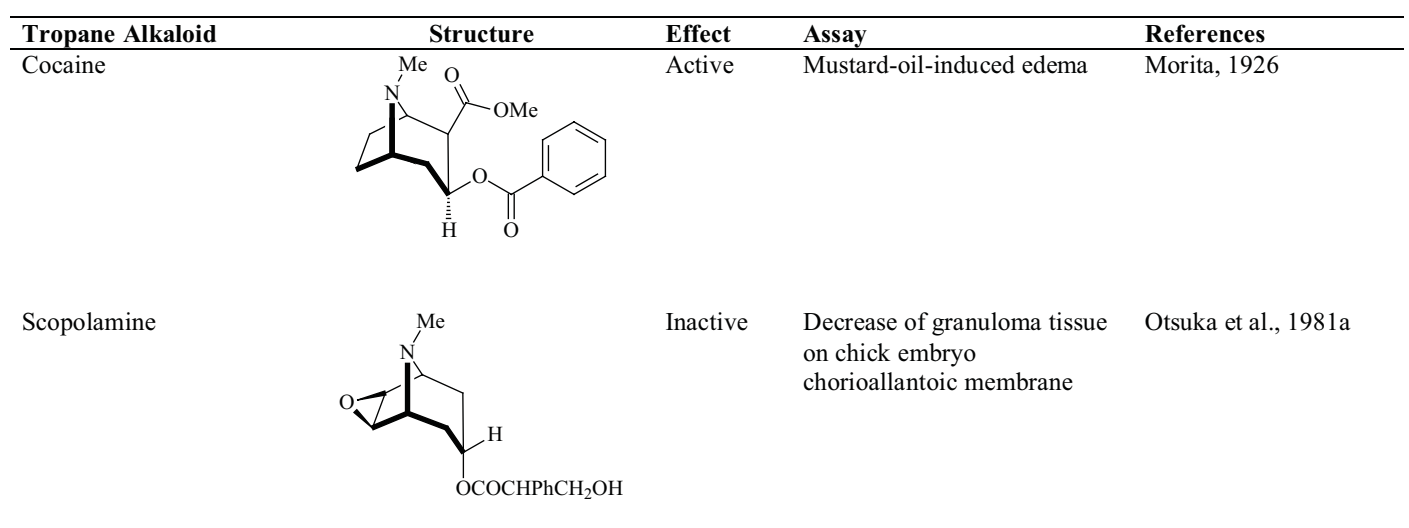

Table 17. Alkaloids imidazolidine summary showing anti-inflammatory activity

\begin{tabular}{llll}
\hline Imidazolidine Alkaloids & Structure & Effect & Assay \\
\hline Histamine & Inactive & $\begin{array}{l}\text { Decrease of granulation tissue on Otsuka et al., 1981a } \\
\text { chick embryo chorioallantoic } \\
\text { membrane }\end{array}$ \\
Pilocarpine & $\begin{array}{l}\text { Decrease of granulation tissue on Otsuka et al., 1981a } \\
\text { chick embryo chorioallantoic } \\
\text { membrane }\end{array}$ & Inactive \\
\hline
\end{tabular}


Table 18. Alkaloids miscelane summary showing anti-inflammatory activity

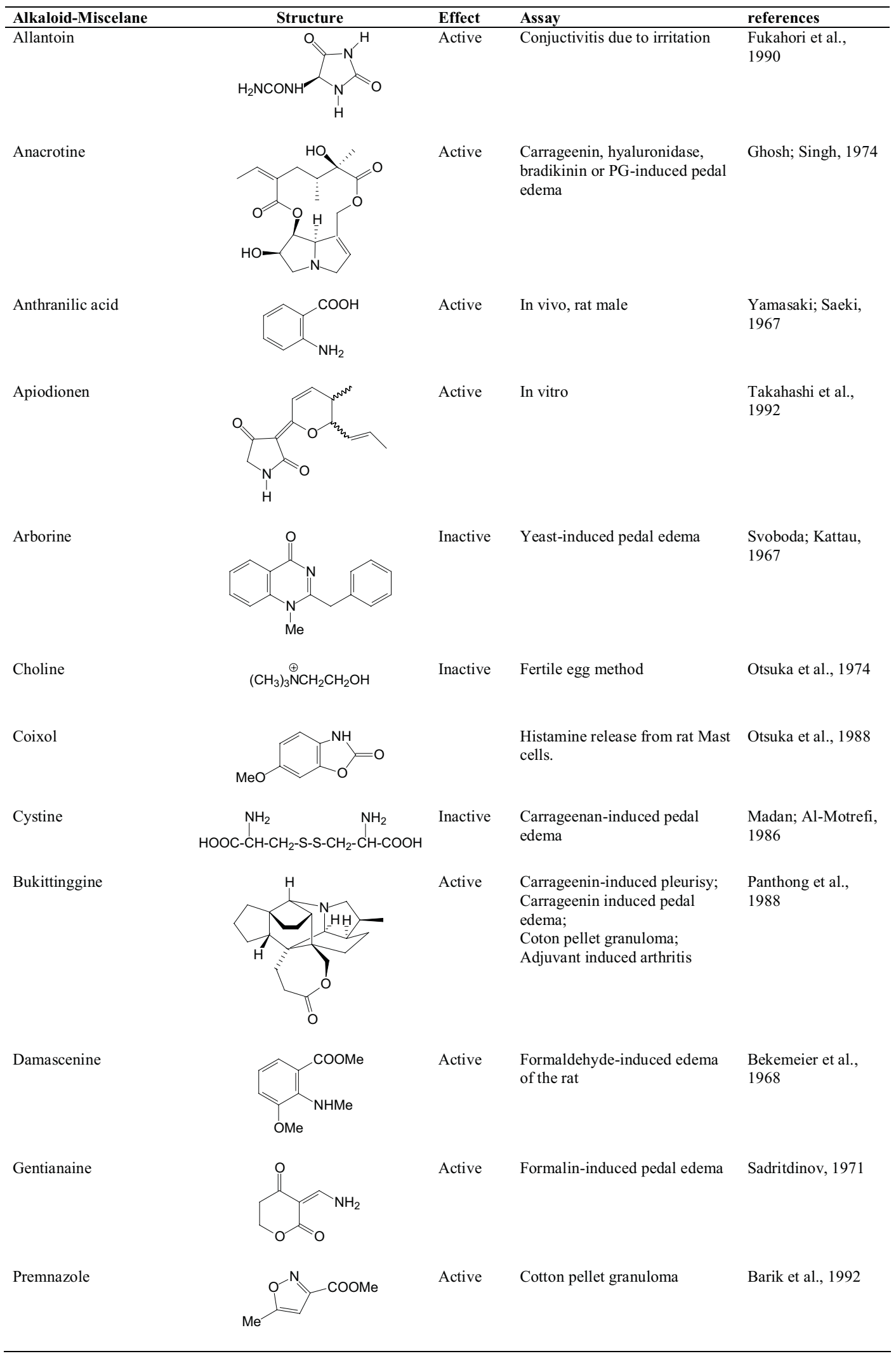




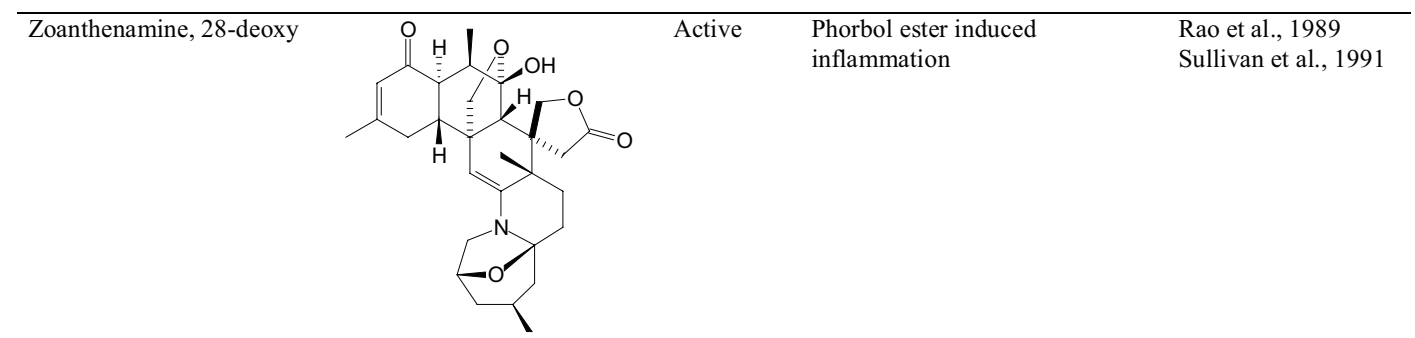

3,506,643.

Blanpin O, Quevauviller A, 1960. Comparative pharmacology of two alkaloids of steroid structure isolated from Funtumia latifolia, funtumine and funtumidine. Annales Pharmaceutiques Francaises 18: 177-192.

Buzas A, Egnell C, Mathieu R, Bourillet F, Potherat JJ, Simon JC 1974. Synthesis and pharmacological properties of new papaveraldine oxime derivatives. Eur J Med Chem Chim 9: 571. C.A. 1975, 82: 171252f.

Byrne JA, Malone MH 1981. Protective effects of cryogenine, lythrine and certain derivatives in croton oil induced inflammation. Proc West Pharmacol Soc 24: 183187.

Castelo-Branco UV, Castelo-Branco UJV, Thomas G, Araújo CC, Barbosa-Filho JM 2000. Preliminary pharmacological studies on three benzoyl amides, constituents of Aniba riparia (Lauraceae). Acta Farm Bonaerense 19: 197-202.

Cerna H, Fiala B, Lenfeld J, Marsalek E, Preininger V, Simanek $\mathrm{V}$ 1984. Isoquinoline alkaloids in local periodontal disease therapy (preliminary notice). Acta Univ Palacki Olomuc Fac Med 107: 159-162.

Chang YC, Malone MH 1971. Anti-inflammatory and liver sulfhydryl content-altering effects of certain nonsteroids in the rat. J Pharm Sci 60: 416-419.

Chang L, Yue Y, Zhou HW 1992. Effects of ligustrazine on microvessel capillary hemodynamics in peritonitis rabbit. Zhongguo Yike Daxue Xuebao 212: 117119.

Chen MC, Chin SC, Wang YC 1965. Effect of lycorine on the pituitary-adrenal system. Yao Hsueh Hsueh Pao 12: 767-771.

Choi HS, Kim HS, Min KR, Kim YS, Lim HK, Chang YK, Chung MW 2000. Inflamamtory effects of fangchinoline and tetrandrine. J Ethnopharmacol 69: 173.

Citoglu G, Tanker M, Gumusel B 1998. Antiinflammatory effects of lycorine and haemanthidine Phytother Res 12: 205-206.

Clarke IMC 1993. Peppering pain. Lancet 342 (8880): 1130.

Cragg GM, Newman DJ, Snader KM 1997. Natural products in drug discovery and development. J Nat Prod 60: $52-60$.

Cruwys SC, Garrett NE, Kidd BL 1995. Sensory denervation with capsaicin attenuates inflammation and nociception in arthritic rats. Neurosci Lett 193: 205207.

De AK, Ghosh JJ 1988. Inflammatory effects of acute and chronic capsaicin treatment on rat paw. Phytother Res 2: 175. C.A. 1989, 110: 109677.
Dekker TG, Fourie TG, Matthee E, Snyckers FO 1988. A morphinan alkaloid from Antizoma angustifolia. $J$ Nat Prod 51: 584.

Denko CW 1992. A role of neuropeptides in inflammation. In: Whicher, J. T. and Evans, S. W. Biochemistry of Inflammation. Kluwer Pub. London. 177-181p.

Endo K, Taguchi T, Taguchi F, Hikino H, Yamahara J, Fujimura H 1979. Antinflammatory principles of Atractylodes rhizomes. Chem Pharm Bull 27: 2954-2958.

Estrada, Horacio R, Aguilar-Santos G 1966. Pharmacologic and chemical studies on gitingensine, a new azasteroidal alkaloid. Journal of the Philippine Medical Association 42: 703-724.

Evans SW, Whicher JT 1992. An overview of the inflammatory response. In: Whicher, J. T. and Evans, S. W. Biochemistry of inflammation. Kluwer Pub. London. $1-15 \mathrm{p}$.

Falcão, HS, Lima IO, Santos VL, Dantas HF, Diniz MFFM, Barbosa-Filho JM, Batista LM 2005. Review of the plants with anti-infl ammatory activity studied in Brazil. Rev Bras Farmacogn 15: 381-391.

Filderman RB, Kovacs BA 1969. Antiinflammatory activity of the steroid alkaloid glycoside, tomatine. Brit $J$ Pharmacol 37: 748-755.

Fuji K, Noide M, Kaku S, Shu T, Chin S 1991. Anti-inflammatory diterpenes from Chrysanthemums. Patent-Japan Kokai Tokkyo Koho-03 86,824, apud Chemical Abstracts 115: 287166k.

Fujiwara R, Ono M, Orita K 1980. The effect of cepharanthine on granuloma formation in the rats. Igaku No Ayumi 11: 1056-1057, apud Chemical Abstracts 94: $58248 \mathrm{u}$.

Fukahori K, Takahashi H, Uchino Y, Eino A 1990. Stable eye drops containing vitamin E, FAD sodium salt, allantoin, and glycyrrhizin. Patent-Japan Kokai Tokkyo Koho-02 311,415, apud Chemical Abstracts 114: 254038

Garcia-Argaez AN, Ramirez-Apan TO, Delgado HP, Velazquez G, Martinez-Vasquez M 2000. Anti-inflammatory activity of coumarins from Decatropis bicolor on TPA ear mice model. Planta Med 66: 279-281.

Ghosh MN, Singh H 1974. Inhibitory effect of a pyrrolizidine alkaloid, crotalaburnine, on rat paw edema and cotton-pellet granuloma. Brit J Pharmacol 51: 503.

Gopalakrishnan C, Shankaranarayan D, Kameswaran L, Natarajan S 1979. Pharmacological investigation of tylophorine, the major alkaloid of Tylophora indica. Indian J Med Res 69: 513.

Gorzalczany S, Acevedo C, Muschietti L, Martino V, Ferraro 
G 1996. Search for antiinflammatory activity in Argentine medicinal plants. Phytomedicine 3: 181184.

Gotteland M, Jimenez I, Brunser O, Guzman L, Romero S, Cassels BK, Speisky H 1997. Protective effect of boldine in experimental colitis. Planta Med 63: 311-315.

Gupta S, Bhakuni DS 1989. Alkaloids of Litsea deccanensis. Planta Med 55: 197.

Haigh CG, Kafy AML, Lewis DA 1984. Observations of the anti-inflammatory action of putrescine. Brit $J$ Pharmacol 82: 283.

Handa SS, Chawla AS, Sharma AK 1992. Plants with antiinflammatory activity. Fitoterapia 63: 3-31.

Hara A, Sakurada T, Sakurada S, Matsumura H, Andoh R, Kisara K 1984. Effects of capsaicin on adjuvantinduced chronic pain in rats. Ann Rep Tohoku Coll Pharm 31: 153-159, apud Chemical Abstracts 103: 153993n.

Harborne JB 1991. Phytochemical methods. 2 ed. Chapman e Hill. 288p.

Henson PM, Murphy RC 1989. Mediators of the inflamatory process. Elsevier, Amsterdam, 404p.

Hikino H, Taguchi T, Fujimura H, Hiramatsu Y 1977. Antiinflammatory principles of Caesalpinia sappan wood and of Haematoxylon compechianum wood. Planta Med 31: 214-220.

Hikino H, Konno C, Takata H, Tamada M 1980. Studies on the constituents of Ephedra. VI. The validity of oriental medicines. XV. Antiinflammatory principle of Ephedra herbs. Chem Pharm Bull 28: 2900-2904.

Hikino H, Takata H, Fujiwara M, Konno C, Ohuchi K 1982. Mechanism of inhibitory action of mesaconitine in acute inflammations. Eur J Pharmacol 82: 65-71.

Hristova M, Istatkova R 1999. Complement-mediated antiinflammatory effect of bisbenzylisoquinoline alkaloid fangchinoline. Phytomedicine 6: 357-362.

Hu ZB, Xu Y, Feng SC, Fan GJ 1979. Studies on the active principles of the fruits of Macleaya cordata (Willd.) R. Br. Yao Hsueh Hsueh Pao 14: 535-540, apud Chemical Abstracts 92: $185791 \mathrm{z}$.

Hwang EJ, Kan EM, Yang KS, Park SB, Kim TH 1990. Effects of ephedrae herba extract on cellular and humoral immune responses. Korean J Pharmacog 213: 256.

Ivanovska N, Philipov S 1996. Study on the anti-inflammatory action of Berberis vulgaris root extract, alkaloid fractions and pure alkaloids. Int J Immunopharmacol 18: 553-561.

Jamieson D, Buckle P 1977. A comparison of anti-inflammatory and other compounds on the spontaneously contracting pregnant rat uterus. J Pharm Pharmacol 29: 112-113, apud Chemical Abstracts 87: 15798m.

Joe B, Lokesh BR 1997. Prophylactic and therapeutic effects of polyunsaturated fatty acids, capsaicin, and curcumin on adjuvant induced arthritis in rats. J Nutr Biochem 87: 397-407.

Kaplan HR, Wolke RE, Malone MH 1967. Anti-inflammatory evaluation of cryogenine. J Pharm Sci 56: 13851392.

Kasahara Y, Hikino H, Tsurufuji S, Watanabe M, Ohuchi K 1985. Anti-inflammatory actions of ephedrines in acute inflammations. Planta Med 51: 325-331.

Kimura M, Suzuki J, Yamada T, Yoshizaki M, Kikuchi T,
Kadota S, Matsuda S 1985. Anti-inflammatory effect of neolignans newly isolated from the crude drug "shin-i" (flos magnoliae). Planta Med 51: 291293.

Kiselev VV 1977. Relationship of structure and activity in the colchicine series. Chem Nat Comp 13: 1-10, apud Chemical Abstracts 87: 47840k.

Kitagawa I, Chen ZL, Yoshihara M, Kobayahsi K, Yoshikawa M, Ono N, Yoshimura Y 1984. Chemical studies on crude processing. III. Aconiti tuber (2). On the constitutents of "pao-fuzi", the processed tuber of Aconitum carmichaeli Debx and biological activities of lipo-alkaloids. Yakugaku Zasshi 104: 858-866.

Kocialski AB, Malone MH, Marozzi FJ 1972. Effects of certain nonsteroid antiinflammatory drugs, tolbutamide, and tetrahydroalstonine on blood-glucose and carrageenin-induced pedal edema in rats. J Pharm Sci 61: 1202-1205.

Kupchan SM, Dasgupta B, Fujita E, King ML 1963. Alkaloids of American lotus, Nelumbo lutea. Tetrahedron 19: 227-232.

Lakdawala AD, Shirole MV, Mandrekar SS, Dohadwalla AN 1988. Immunopharmacological potential of rohitukine: a novel compound isolated from the plant Dysoxylum binectariferum. Asia Pac J Pharmacol 32: 91-98, Chemical Abstracts 109: 183182a.

Lanhers MC, Joyeux M, Soulimani R, Fleurentin J, Sayag M, Mortier F, Younos C, Pelt JM 1991. Hepatoprotective and anti-inflammatory effects of a traditional medicinal plant of chile, Peumus boldus. Planta Med 57: 110.

Leboeuf M, Cave A, Forgacs P, Tiberghien R, Provost J, Touche A, Jacquemin H 1982. Alkaloids of the Annonaceae. 40. Chemical and pharmacological study of the alkaloids of Annona montana Macf. Plant Med Phytother 16: 169-184, apud Chemical Abstracts 97: 52498r.

Lee EB, Shin KH, Woo WS 1984. Pharmacological study on piperine. Arch Pharm Res 72: 127-132.

Lenfeld J, Kroutil M, Marsalek E, Slavik J, Preininger V, Simanek V 1981. Antiinflammatory activity of quaternary benzophenanthridine alkaloids from Chelidonium majus. Planta Med 43: 161-165.

Lewis DA 1989. Anti-flamatory drugs from plant and marine sources. Birkhause Verlag, Basel.

Li SY, Ling LH, Teh BS, Seow WK, Thong YH 1989. Antiinflammatory and immunosuppressive properties of the bis-benzylisoquinolines: In vitro comparisons of tetrandrine and berbamine. Int J Immunopharmacol 11: 395-401.

Lim JK, Lee EB, Woo WS, Lee KR, Ma ES 1994. Analgesic, anti-inflammatory and antiviral effects of melandrin derivatives. Yakhak Hoe Chi 38: 345-350.

Luo B, Kobayashi S, Kimura I, Kimura M 1991. Inhibitory effects on angiogenesis and pouch fluid exudation by aconite alkaloids in adjuvant-induced inflammation of the mouse. Phytother Res 5: 231-233.

Ma JJ, Si LF, Ding Y, Lin ZB, Chen XR, Han CL, Peng QS, Fang $Y$ 1991. Inhibition of type I-IV allergic reactions by oxymatrine. Beijing Yike Daxue Xuebao 23: 445447.

McCarthy GM, McCarty DJ 1992. Effect of topical capsaicin in the therapy of painful osteoarthritis of the hands. $J$ 
Rhematol 19: 604-607.

Madan BR, Al-Motrefi A 1986. Anti-inflammatory actions of some amino acids and their derivatives. IRCS Med Sci 14: 288-285, apud Chemical Abstracts 104: $218520 \mathrm{~g}$.

Malkinson FD 1982. Colchicine: new uses of an old, old drug. Arch Dermatol 11: 453-457.

Mascolo N 1987. Biological screening of Italian medicinal plants for anti-inflammatory activity. Phytother Res 1: 28-31.

Matsuda H, Tokuoka K, Shiomoto H, Kubo M 1997. Antiinflammatory activities of dehydrocorydaline isolated from Corydalis tuber. Nat Med 51: 293297.

Matsuda H, Yoshikawa M, Ko S, Iinuma M, Kubo M 1998. Antinociceptive and antiinflammatory activities of evodiamine and rutaecarpine Nat Med 52: 203208.

Mikami M, Kitahara M, Katano M, Ariki Y, Mimaki Y, Sashida Y, Yamazaki M, Yui S 1999. Suppressive activity of lycoricidinol (narciclasine) against cytotoxicity of neutrophil-derived calprotectin, and its suppressive effect on rat adjuvant arthritis model. Biol Pharm Bull 22: 674-678.

Millaire A, Ducloux G 1992. Treatment of acute and recurrent pericarditis with colchicine. Lancet 340: 14581459.

Mimura T, Maeda K, Hariyama H, Aonuma S, Satake M, Fujita T 1982. Studies on biological activities of melanin from marine animals. I. Purification of melanin from Ommastrephes bartrami Lesuel and its inhibitory activity on gastric juice secretion in rats. Chem Pharm Bull 30: 1381-1386.

Molokhova LG, Suslina ML, Datskovskii SB, Figurkin BA 1973. Antiinflammatory effect of fumitory alkaloids. Tr Permsk Gos Med Inst 118: 26-28.

Montanari AM, Fenical W, Lindquist N, Lee AY, Clardy J 1996. Volutamides A-E, halogenated alkaloids with atifeedant properties from the atlantic Bryozoan Amathia convoluta.Tetrahedron 52: 5371-5380.

Moon TC, Murakami M, Kudo I, Son KH, Kim HP, Kang SS, Chang HW 1999. A new class of Cox-2 inhibitor, rutaecarpine from Evoida rutaecarpa. Inflamm Res 48: 621-625.

Morita G 1926. Antiinflammatory effect of drugs. Folia Jap Pharmacol 3: 233-244.

Munjudar AM, Dhuley JN, Deshmukh VK, Raman PH, Naik SR 1990. Anti-inflammatory activity of piperine. Jpn J Med Sci Biol 43: 95-100, Chemical Abstracts 114: 178024w.

Murakoshi I, Fujii Y, Kawamura H, Maruyama H 1992. Lupine alkaloids as anti-inflammatory agents. Patent-Japan Kokai Tokkyo Koho-04 295,479, apud Chemical Abstracts 119: 45773u.

Murayama M, Mori T, Bando H, Amiya T 1991. Studies on the constituents of Aconitum species. IX. the pharmacological properties of pyro-type aconitine alkaloids, components of processed aconit powder 'kako-bushi-matsu': analgesic, antiinflammatory and acute toxic activities. J Ethnopharmacol 35: 159-164.

Naidovich LP, Trutneva EA, Tolkachev ON, Vasil'eva VD 1976. Chemical composition of indigenous species of the
Berberidaceae family. Interrelation of chemical structure and pharmacological activity. Farmatsiya (Moscow) 25: 33-38.

Naik RG, Kattige SL, Bhat SV, Alreja B, De Souza NJ, Rupp RH 1988. An antiinflammatory cum immunomodulatory piperidinylbenzopyranone from Dysoxylum binectariferum: isolation, structure and total synthesis.Tetrahedron 44: 2081-2086.

Nikolov R, Peneva M 1978. Study of analgesic and antiiflammatory action of glaucine. Eksp Med Morfol 17: 190-194, apud Chemical Abstracts 91: 274w.

Noamesi BK, Bamgbose SOA 1983. Cryptolepine - A pharmacological review. First Int Seminar Cryptolepine 41-51.

Oletta SA 1964. New alkaloids from Holarrhena species. Patent-GB 948485, 6 pp.

Omaye ST, Kosersky DS, Malone MH 1972. Proc West Pharmacol Soc 15: 205-208.

Onai N, Tsunokawa Y, Suda M, Watanabe N, Nakamura K, Sugimoto Y, Kobayashi Y 1995. Inhibitory effects of bisbenzylisoquinoline alkaloids on induction of proinflammatory cytokines, interleukin-1 and tumor necrosis factor-alpha. Planta Med 61: 497-501.

Ono M 1994. Inflammation inhibitors containing cepharanoline or berbamine. Patent-Japan Kokai Tokkyo Koho-06 211,661 .

Ono M, Tanaka N, Moriyasu T 1994a. Anti-inflammatory action of cepharanthine ointment ingredient in experimental animals; studies for the acute inflammation. Ensho 14: 431-438, apud Chemical Abstracts 122: 71610x

Ono M, Tanaka N, Moriyasu T 1994b. Anti-inflammatory action of cepharanthine ointment ingredient in experimental animals: Studies on chronic inflammation and TNFalpha production. Ensho 14: 425-429.

Oriowo MA 1982. Anti-inflammatory activity of piperonyl4-acrylic isobutyl amide, an extractive from Zanthoxylum zanthoxyloides. Planta Med 44: 5456.

Otsuka H, Tsukui M, Matsuoka T, Goto M, Fujimura H, Hiramatsu Y, Sawada T 1974. Studies on antiinflammatory agents. anti-inflammatory screening by fertile egg method. Yakugaku Zasshi 94: 796.

Otsuka H, Fujimura H, Sawada T, Goto M 1981a. Studies on anti-inflammatory agents. Part 2. anti-inflammatory constituents from rhizome of Coptis japonica Makino. Yakugaku Zasshi 101: 883-890.

Otsuka H, Fujioka S, Komiya T, Goto M, Hiramatsu Y, Fujimura H 1981b. Studies on anti-inflammatory agents. Part 5. A new anti-inflammatory constituent of Pyracantha crenulata Roem. Chem Pharm Bull 29: 3099-3104.

Otsuka H, Komiya T, Fujioka S, Goto M, Hiramatsu Y, Fujimura H 1981c. Studies on anti-inflammatory agents. Part 3. An antiinflammatory constituent of the genus Acer. Yakugaku Zasshi 101: 1108-1112.

Otsuka H, Fujioka S, Komeya T, Mizuta E, Takamoto M 1982. Studies on anti-inflammatory agents. Part 6. Anti-inflammatory constituents of Cinnamomum sieboldii Meissn. Yakugaku Zasshi 102: 162-172.

Otsuka H, Hirai Y, Nagao T, Yamasaki K 1988. Antiinflammatory activity of benzoxazinoids from roots 
of Coix lachryma-jobi var. ma-yuen. J Nat Prod 51: 74-79.

Panthong A, Kanjanapothi D, Thitiponpunt Y, Taesotikul T, Arbain D 1984. Anti-inflammatory activity of the alkaloid anabasamine. Dokl Akad Nauk Uzssr 198: 45-47, apud Chemical Abstracts 102: 125224g.

Panthong A, Kanjanapothi D, Thitiponpunt Y, Taesotikul T, Arbain D 1998. Anti-inflammatory activity of the alkaloid bukittinggine from Sapium baccatum. Planta Med 64: 530-535.

Parmely MJ, Zhou WW, Edwards III CK, Borcherding DR, Silverstein R, Morrison DC 1993. Adenosine and a related carbocyclic nucleoside analogue selectively inhibit tumor necrossis factor-alpha production and protect mice against endotox challenge. J Immunol 151: 389-396.

Parnham MJ 1991. Drugs in inflammation. Birkhauser Verlag, Basel.

Perdue GP, Blomster RN, Blake DA, Farnsworth NR 1979. South American plants. II. Taspine, isolation and antiinflammatory activity. J Pharm Sci 68: 124126.

Persinos GJ 1972. Anti-inflammation compositions containing taspine or acid salts thereof and method of use. Patent-US-3,694,557.

Pinto L, Borrelli F, Bombardelli E, Cristoni A, Capasso F 1998. Anti-inflammatory, analgesic and antipyretic effects of glaucine in rats and mice. Pharm Pharmacol Commun 4: 502-505.

Pitts JR 1995. Colchicine therapy for palmar fibromatosis. $N$ Engl J Med 333: 393.

Plotnick S, Huppert AS, Kantor G 1989. Colchicine and leukocytoclastic vasculitis. Arthritis Rheumatism 32: 1489-1490.

Rao CH, Rao DV, Raju VSN, Sullivan BW, Faulkner DJ 1989. Two new alkaloids from an Indian species of Zoanthus. Heterocycles 28: 103-106.

Raychaudhuri A, Colombo C, Pastor G, Wong M, Jeng AY 1991. Effect of capsaicin on carrageenan-induced inflammation in rat pleurisy and exudate substances p level. Agents Actions 34: 251-253.

Reddy ACP, Lokesh BR 1994. Studies on anti-inflammatory activity of spice principles and dietary n-2 polyunsaturated fatty acids on carrageenan-induced inflammation in rats. Ann Nutr Metab 38: 349-358, apud Chemical Abstracts 122: 104726v.

Revesz J, Bilkei-Gorzo A, Kormoczy PS 1992. The antiinflammatory effect of therophylline. Pharmacol Res 25: 262-263.

Rios JL, Giner RM, Villar A 1989. Isolation and identification of an antiinflammatory principle from Santolina chamaecyparissus. Phytother Res 35: 212-214.

Sadritdinov F 1971. Comparative study of the antinflammatory properties of alkaloids from Gentiana plants. Farmakol Alkaloidov Glikozidov 146-148.

Sadritdinov F, Sultanov MB 1971. Antiinflammatory activity of the alkaloids thalmine and $O$-methylthalieberine. Farmakol Alkaloidov Glikozidov 120.

Sadritdinov F 1972. Antiinflammatory activity of fetidine. Farmakol Alkaloidov Ikh Proizvod 154.

Sadritdinov FS 1974. Comparative pharmacological study of thalicsimine, tetrandrine, and demethyltetrandrine. Med Zh Uzb 54, apud Chemical Abstracts 82:
$80578 \mathrm{a}$.

Sadritdinov FS 1980. Pharmacological properties of alkaloids from a Berberis integerrima plant. Med Zh Uzb 2: 54-55, apud Chemical Abstracts 92: 174599s.

Saeed SA, Simjee KU, Mahmood F, Rahman NN 1993. Dual inhibition of platelet-activating factor and arachidonic acid metabolism by ajmaline and effect on carrageenan-induced rat paw oedema. J Pharm Pharmacol 45: 715-719.

Saidkasymov T, Sultanov MB, Umarova SH 1971. Effect of the alkaloids edpetiline and petiline on the course of experimental arthritis in rats. Farmakol Alkaloidov Glikozidov 19: 187.

Saidkasymov T 1978. Pharmacology of the alkaloid veralosine. Farmakol Prir Veshchestv 71-74.

Sais G, Vidaller A, Jucgla A, Gallardo E, Peyri J 1995. Colchicine in the treatment of cutaneous leukocytoclastic vasculitis: results of a prospective, randomized controled trial. Arch Dermatol 131: 1399-1402.

Saito H, Ueyama T, Naka N, Yagi J, Okamoto T 1982. Pharmacological studies of ignavine, an Aconitum alkaloid. Chem Pharm Bull 30: 1844-1850.

Saito H, Saito S, Okamoto T 1983. Ignavine as an analgesic, antipyretic, and anti-inflammatory drug. PatentJapan Kokai Tokkyo Koho-58 42,923.

Salama AM, Lopez MS, Gutierrez M, Achenbach H 1987. Antinflammatory and cardio activie glucosides from Sechium edule. Rev Latinoamer Quim 18: 132-133.

Santos FA, Rao VSN 1998. Study of the anti-pyretic effect of quinine, an alkaloid effective against cerebral malaria, on fever induced by bacterial endotoxin and yeast in rats. $J$ Pharm Pharmacol 50: 225-229.

Sawynok J, Reid AR, Doak GJ 1995. Caffeine antiociception in the rat hot-plate and formalin tests and locomotor stimulation: involvement of nonadrenergic mechanisms. Pain 61: 203-213.

Schinitsky MR 1980. Vinblastine in rheumatoid arthritis. Patent-US-4,208,414.

Seow WK, Li ST-Ying, Thong YH 1986. Inhibitory effect of tetrandrine on human neutrophil and monocyte adherence. Immun Lett 13: 83-88.

Seow WK Ferrante A, Li SY, Thong YH 1988. Antiphagocytic and anti-oxidant properties of the plant alkaloid tetrandrine. Int Archs Allergy Appl Immun 85: 404409.

Seow WK, Ferrante A, Li SY, Thong YH 1989. Suppression of human monocyte interleukin 1 production by the plant alkaloid tetrandrine. Clin Exp Immun 75: 4751.

Shin KH, Yun-Choi HS, Chung HS, Koo KA, Kim D 1996. Antiinflammatory and analgesic effects of higenamine, a component of Aconiti tuber. Nat Prod Sci 21: 24-28.

Somei M 1987. Processes for the preparation of (+)-paniculidine $\mathrm{b}$ as an analgesic or inflammation inhibitor. PatentJapan Kokai Tokkyo Koho-62 111,966, apud Chemical Abstracts 108: 94825w.

Sullivan BW, Faulkner DJ, Rao CB, Rao DV, Raju VSN 1991. New alkaloids from an Indian species of Zoanthus. Bioact Compd Mar Org Indo-Us Symp 219-224.

Sullivan P, Bekir S, Jaffar Z, Page C, Jeffery, Costello J 1994. Anti-inflammatory effects of low-dose oral theophylline in atopic asthma. Lancet 343 (8904): 
1006-1008

Sung CY, Chi HC, Liu KT 1958. The Pharmacology of gentianine. I. Antiphlogistic effect and acion of pituitary-adrenal function of the rat. Sheng Li Hsueh Pao 22: 201-205.

Suzuki S, Kishi S, Nakasako T, Ohyanagi Y 1983. Antiinflammatory effects of polyamines. Ensho 34: 409-410.

Svoboda GH, Kattau RW 1967. Alkaloids of Acronychia baueri (Bauerella australiana) III. CNS depressant principles. Lloydia 30: 364-371.

Takahashi H, Shiraishi A, Iizuka Y, Furuya K, Kagasaki T 1992. Manufacture of anticancer and anti-inflammatory apiodionen with apiosordaria. Patent-Japankokai Tokkyo Koho-04 49,289.

Takigawa M, Miyachi Y, Uehara M, Tagami H 1982. Treatment of pustulosis palmaris et plataris with oral doses of colchicine. Arch Dermatol 118: 458-460

Tan H, Zhang B 1985. An experimental study of matrine's antihypertensive effect. Chin J Integ Trad West Med 5: 108-110.

Tang XC, Lin ZG, Cai W, Chen N, Shen L 1984. Antiinflammatory effect of 3-acetylaconitine. Chung-Kuo Yao Li Hsueh Pao 5: 85-89, apud Chemical Abstracts 101: 17013b.

Teh BS, Ioannoni B, Seow WK, McCormack JG, Thong YH 1989. Supresion by tetrandrine of human platelet aggregation induced by platelet-activating factor and othe stimulants. Int Archs Allergy Appl Immun 88: 267-272.

Teh BS, Seow WK, Li SY, Thong YH 1990. Inhibition of prostaglandin and leukotriene generation by the plant alkaloids tetrandrine and berbamine. Int $J$ Immunopharmac 12: 321-326.

Tits M, Damas J, Quetin-Leclercq J, Angenot L 1991. From ethnobotanical uses of Strychnos henningsii to antiinflammatories, analgesics and antispasmodics. J Ethnopharmacol 34: 261-267.

Tulyaganov N, Sadritdinov F 1971. Seasonal fluctuations in the activity of antiinflammatory substances. Farmakol Alkaloidov Glikozidov: 125

Ulrichova J, Walterova D, Simanek V 1984. Molecular mechanisms of the biological activity of quaternary benzophenanthridine and protoberberine alkaloids. Acta Univ Palacki Olomuc Fac Med 106:31-37, apud Chemical Abstracts 102: 1a.

Wang M, Huang YJ, Zhang TH, Tong ZQ 1996. Anti-allergic, anti-histamine and anti-inflammatory effects of compound pseudoephedrine. Shenyang Yaoke Daxue Xиebao 132:129-133.

Willenborg GO, Cowden DB, Parish CR 1990. Use of castanospermine as an anti-inflammatory and immunosuppressant agent. Patent-Pct Int Appl-90 01,319, apud Chemical Abstracts 114: 35993a.

Willianson EM 1996. Selection, preparation and pharmacological evaluation of plant material. John Wiley and Sons. Chichester, Eng.

Wong CW, Seow WK, Zeng TS, Halliday JJ, Thong YH 1991. Comparative immunopharmacology and toxicology of the bisbenzylisoquinoline alkaloids tetrandrine and berbamine. Int J Immunopharmacol 13: 579585.

Wong CW, Seow WK, O’callaghan JW, Thong YH 1992.
Comparative effects of tetrandrine and berbamine on subcutaneous air pouch inflammation induced by interleukin 1, tumour necrosis factor and plateletactivating factor. Agents Actions 36: 112-118.

Wu YC, Uw TS, Niwa M, Lu ST, Hirata Y, Mc Phail DR, Mc Phail AT, Lee KH 1988. Structure and stereochemistry of thalicsiline, a new antiinflammatory C-20 diterpenoid alkaloid from Thalictrum sessile. Heterocycles 27: 1813-1816.

Yamahara J, Sawada T, Kozuka M, Fujimura H 1974a. Pharmacological actions of the alkaloids of Menispermaceous plants. I. Pharmacological actions of tetrandrine. Shoyakugaku Zasshi 28: 8395, apud Chemical Abstracts 83: 53481c.

Yamahara J, Sawada T, Fujimura H 1974b. Pharmacological actions of the alkaloids of Menispermaceous plants. II. Pharmacological actions of trilobine and isotrilobine. Shoyakugaku Zasshi 28: 96-101, apud Chemical Abstracts 83: 53482d.

Yamamoto S, Kiyoto I, Aizu E, Nakadate T, Hosoda Y, Kato R 1989. Differential inhibition by staurosporine, a potent protein kinase c inhibitor, of 12-Otetradecanoylphorbol-13-acetate-caused skin tumor promotion epidermal ornithine decarboxylase induction, hyperplasia and inflammation. Carcinogenesis 10: 1315-1322.

Yamasaki H, Saeki K 1967. Inhibition of mast-cell degranulation by anti-inflammatory agents. Arch Int Pharmacodyn Ther 105: 166, apud Chemical Abstracts 67: $72108 \mathrm{x}$.

Yang JJ, Yu DQ 1990. Synthesis of ganoderma alkaloid A and B. Yao Hsueh Hsueh Pao 25: 555-559, apud Chemical Abstracts 114: 164574p.

Yasukawa K, Takido M, Ikekawa T, Shimada F, Takeuchi M, Nakagawa S 1991. Relative inhibitory activity of berberine-type alkaloids against 12o-tetradecanoylphorbol-13-acetate-induced inflammation in mice. Chem Pharm Bull 39: 14621465 .

Yasukawa K, Akasu M, Takeuchi M, Takido M 1993. Bisbenzylisoquinoline alkaloids inhibit tumor promotion by 12-O-tetradecanoylphorbol-13acetate in two-stage carcinogenesis in mouse skin.: Oncology 50: 137-140.

Yoshino S, Blake DR, Bacon PA 1984. The effect of desferrioxamine on antigen-induced inflammation in the rat air pouch. J Pharm Pharmacol 36: 543545.

Zhang DH, Li HY, Sang WL 1982. Studies on constituents of fu zi (Aconitum carmichaeli). A traditional chinese medicine. II. Chemical constituents of a processed a carmichaeli, bai fu pian. Chung Ts'ao Yao 13: 481484.

Zhang J 1985. Yuохие Xuebao 20: 423, apud Chemical Abstracts 105: 90930.

Zhang MF, Shen YQ, Tang CK 1990. Anti-inflammatory and analgesic actions of berberine. Tianran Chanwu Yanjiu Yu Kaifa 21: 49-53, apud Chemical Abstracts 115: $197979 y$. 